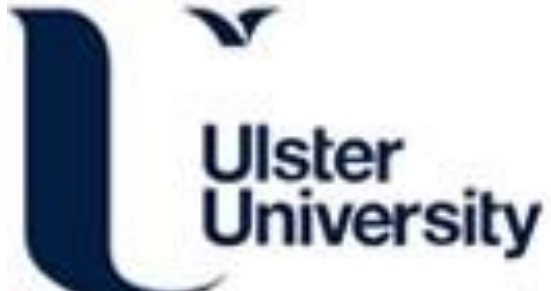

\section{Porous yolk-shell particle engineering via nonsolvent-assisted trineedle coaxial electrospraying for burn-related wound healing}

Zhang, C., Li, Y., Hu, Y., Peng, Y., Ahmad, Z., Li, J. S., \& Chang, M. W. (2019). Porous yolk-shell particle engineering via nonsolvent-assisted trineedle coaxial electrospraying for burn-related wound healing. ACS Applied Materials and Interfaces, 11(8), 7823-7835. https://doi.org/10.1021/acsami.8b22112

Link to publication record in Ulster University Research Portal

Published in:

ACS Applied Materials and Interfaces

Publication Status:

Published (in print/issue): 27/02/2019

DOI:

10.1021/acsami.8b22112

Document Version

Author Accepted version

\section{General rights}

Copyright for the publications made accessible via Ulster University's Research Portal is retained by the author(s) and / or other copyright owners and it is a condition of accessing these publications that users recognise and abide by the legal requirements associated with these rights.

\section{Take down policy}

The Research Portal is Ulster University's institutional repository that provides access to Ulster's research outputs. Every effort has been made to ensure that content in the Research Portal does not infringe any person's rights, or applicable UK laws. If you discover content in the Research Portal that you believe breaches copyright or violates any law, please contact pure-support@ulster.ac.uk. 


\section{Porous Yolk-Shell Particle Engineering via}

\section{Nonsolvent Assisted Tri-Needle Co-axial \\ Electrospraying For Burn Related Wound Healing}

Chunchen Zhang ${ }^{\dagger}+$, Yudong $\mathrm{Li}^{\dagger}$, Yejun Hu${ }^{\perp}$, Yu Peng ${ }^{\S}$, Zeeshan Ahmad ${ }^{\xi}$, Jing-Song Li $i^{\dagger}$, Ming-

Wei Chang ${ }^{\dagger} \neq^{*}$

${ }^{\dagger}$ Key Laboratory for Biomedical Engineering of Education Ministry of China, Zhejiang

University, Hangzhou, 310027, PR China

Zhejiang Provincial Key Laboratory of Cardio-Cerebral Vascular Detection Technology and

Medicinal Effectiveness Appraisal, Zhejiang University, Hangzhou, 310027, PR China

${ }^{+}$School of Medicine, Zhejiang University, Hangzhou, 310027, PR China

${ }^{\S}$ College of Civil Engineering and Architecture, Zhejiang University, Hangzhou, 310027, PR

China

${ }^{\xi}$ Leicester School of Pharmacy, De Montfort University, The Gateway, Leicester, LE1 9BH, UK

KEYWORDS: polymer-based particles; porous yolk-shell microparticles; nonsolvent method; tri-needle coaxial electrospraying; burn wound healing. 


\section{ABSTRACT:}

Yolk-shell particles (YSPs) have attracted increasing attention from various research fields because of their low density, large surface area and excellent loading capacity. However, the fabrication of polymer-based porous yolk-shell particles remains a great challenge. In this work, multi-functional polycaprolactone (PCL) yolk-shell particles were produced using tri-needle coaxial electrospraying with a simple nonsolvent process. $\mathrm{TiO}_{2}-\mathrm{Ag}$ nanoparticles and Ganoderma lucidum polysaccharides (GLP) were encapsulated into the outer shell of the YSPs as the major antibacterial and antioxidant component, while iron oxide $\left(\mathrm{Fe}_{3} \mathrm{O}_{4}\right)$ nanoparticles were incorporated into the inner core to act as a photothermal agent. The morphology and structure, chemical composition, biocompatibility, antioxidant and antibacterial effects of the fabricated YSPs, photothermal effects and the release profile of the encapsulated GLP were studied in vitro. Furthermore, the in vivo wound healing effects of the YSPs and laser-assisted therapy were explored based on a burn wound model on c57 mice.

\section{INTRODUCTION}

In the past decade, micro- and nanoparticles with various structures and functions have attracted widespread attention in biomedical fields ${ }^{1-2}$, including but not limited to serving as drug release matrices for oral capsules or injectable agents ${ }^{3}$, being micro-scaffold for $3 \mathrm{D}$ cell culture ${ }^{4}$ and acting as the platform for multimodal imaging and therapy ${ }^{5}$. The functionalities of the particles largely depend on their surface morphology and internal structure ${ }^{6-8}$. Micro- and nanoparticles with various or unique morphologies (e.g. Janus ${ }^{8}$, multilayered ${ }^{9}$, hollow ${ }^{10}$, porous $^{10}$, mushroom-shape ${ }^{11}$, single-hole ${ }^{12}$ and yolk-shell ${ }^{13}$ ) have gained specific interest due to these morphologies allowing for further development of new and complex functions of the 
resulting particles ${ }^{10,14}$. For instance, pores of such particles accelerate drug release rate ${ }^{15}$ and provide a large area for cells to attach and proliferate ${ }^{16}$; the void space of hollow particles provide opportunities for macromolecule encapsulation ${ }^{17}$.

YSPs have caught much attention in recent years due to their intrinsic configuration consisting of a movable core with an encircled porous shell; allowing them to possess outstanding advantages, including low density, large specific area and excellent loading capacity. ${ }^{18}$ As a result of these, they have become attractive candidates for a great number of biomedical applications including biosensing ${ }^{19}$, drug delivery and theranostics ${ }^{20}$.

Methods of synthesizing YSPs are generally divided into four categories: hard-templating synthesis, soft-templating synthesis, self-templating synthesis and multimethod combination synthesis ${ }^{20}$. Most of these methods are multistep processes and require additional reaction conditions such as injection of inert gas $^{21}$ or maintaining reaction temperatures ${ }^{22}$. These factors can make it extremely difficult to successfully fabricate YSPs. Current research shows the fabrication of YSPs is dependent on the use of metal particles ${ }^{23}$, non-metal particles ${ }^{24}$ or oxides $^{25-26}$. However, the utilization of these has proven to show in vivo toxicity ${ }^{27}$. As a result, only polymeric materials are considered for particle engineering for appropriate biosafety, biocompatibility and biodegradation ${ }^{28}$. The use of polymeric materials in YSP fabrication has not yet been exploited in publications.

Tri-needle co-axial electrospraying is a facile and versatile method to produce multilayered (more specifically tri-layered) polymeric particles in one-step at ambient temperature ${ }^{29}$. This engineering method allows particles to be collected with a solvent; proving to be a cost-effective and convenient way of yielding porous polymeric particles as found in previous studies ${ }^{30}$. 
Polycaprolactone (PCL) is a FDA proved biomaterial ${ }^{31}$, which has been widely used in biomedical applications due to its ability to form particles of various structures ${ }^{32}$.

$\mathrm{TiO}_{2}$-Ag nanoparticles are metal/semiconductor nanocomposites which are biologically safe, exhibit low toxicity and relatively simple to fabricate. ${ }^{33}$ Due to the presence of silver, these nanoparticles have also shown to have promising antibacterial properties ${ }^{33}$. Combining the advantages of both $\mathrm{TiO}_{2}$ and silver can overcome the adverse side effects of silver ions on human health ${ }^{34}$.

Polysaccharides have been widely reported to successfully aid in wound healing due to their biocompatibility, low toxicity and antioxidant activity ${ }^{35}$. G. lucidum polysaccharides (GLPs) are natural bioactives well known for their excellent antioxidant properties and the pharmaceutic effects on promoting diabetic wound healing ${ }^{36}$.

Iron oxide nanoparticles $\left(\mathrm{Fe}_{3} \mathrm{O}_{4}\right)$ are broadly used in the biomedical remit including imaging, drug delivery control, magnetic targeting and photothermal therapy due to its good biocompatibility and low toxicity ${ }^{37}$.

In this work, polymer-based YSPs were fabricated using tri-needle co-axial electrospraying, To evaluate the toxicity and potential biomedical application of the resulting YSPs, PCL was selected as the carrier material for the core and the shell with $\mathrm{TiO}_{2}-\mathrm{Ag}$ nanoparticles and GLP being encapsulated within the shell as the major antibacterial and antioxidant component. $\mathrm{Fe}_{3} \mathrm{O}_{4}$ nanoparticles were incorporated into the core to act as a photothermal agent. The morphology, structure, chemical composition, biocompatibility, antioxidant and antibacterial properties of the fabricated YSPs were studied in vitro alongside the photothermal effects and the release profile of the encapsulated GLP. Furthermore, the in vivo wound healing effects of the YSPs and laserassisted therapy using the YSPs were tested using a burn wound model on c57 mice. 


\section{MATERIALS AND METHODS}

\subsection{Materials and animals.}

PCL $(\mathrm{Mw}=45000 \mathrm{~g} / \mathrm{mol})$ was purchased from Sigma-Aldrich, St Louis. Ethyl cellulose (EC), $\mathrm{Fe}_{3} \mathrm{O}_{4}$ (nanospheres with diameters of about $20 \mathrm{~nm}, \mathrm{MNP}$ ) and Triton X-100 was purchased from Aladdin Chemistry Co., Ltd., Shanghai, China. GLP was purchased from Beijing Jingcheng Biotechnology Co., Ltd., Beijing, China. $\mathrm{TiO}_{2}-\mathrm{Ag}$ NPs (white powder, particle diameter 30 nm, constituting 3 w/w \% silver content) were purchased from Hangzhou Wanjing New materials Co., Ltd., Hangzhou, China. Ethanol, Phosphate-buffered saline (PBS) and glacial acetic acid (HAc) and glycerol were supplied by Sinopharm Chemical Reagent Co., Ltd., Shanghai, China. Modified Eagle's medium (MEM, Gibco) and fetal bovine serum (FBS) were obtained from Invitrogen, CA. Cell Counting Kit-8 (CCK-8) was purchased from Dojindo Molecular Technologies, Inc. (Kumamoto, Japan). Ultrapure water was produced with a Millipore Milli-Q Reference ultrapure water purifier (Molsheim, France).

Reactive oxygen species (ROS) assay kit was bought from Nanjing JianCheng Bioengineering Institute. Rhodamine-phalloidin was obtained from Shanghai Yeasen Biotechnology Co., Ltd (Shanghai, China). DAPI dihydrochloride was a product of Beyotime Biotechnology (Shanghai, China). Escherichia coli (E. coli) was obtained from Maojie Microbial Sci. \& Tech. Co., Ltd., Nanjing, China. Staphylococcus aureus (S. aureus) was purchased from National Center for Medical Culture Collections, Beijing, China. Violet Red Bile agar and Baird-Parker agar both were acquired from Hope Bio-Technogy Co., Ltd., Qingdao, China.

Adult male C57 mice ( $\mathrm{N}=18$; 6-8 weeks old; body weight over $16 \mathrm{~g}$ ) were obtained from Shanghai Silaike Experiment Animal Co., Ltd. (Shanghai, China). Animal experiments were 
conducted in animal room with Specific Pathogen Free (SPF) standards. All animal experiment protocols were approved by Institutional Animal Care and Use Committee.

\subsection{Yolk-shell microparticle preparation}

The particles prepared in this work were all fabricated using a tri-needle co-axial electrospraying system comprising a nozzle of three concentrically aligned stainless steel capillaries, a high voltage (Glassman High Voltage Inc), three precision syringe pumps (KD Scientific KDS100) and a ground steel ring (diameter $=5 \mathrm{~cm}$ ). The three different formations were injected into the capillaries via silicone tubing; connecting the syringe to the corresponding capillary inlet. The power supply was used to introduce an electrical field between the outlet of the nozzle and the ground electrode. A high speed digital camera (Baumer TXG02C, Germany) connected with the computer was used to observe the real-time jetting behavior during the co-

axial electrospraying process. The applied voltage was kept at $12.0 \mathrm{kV}$ and the flow rates were $5.0,1.5,0.8 \mathrm{~mL} / \mathrm{h}$ for outer, intermediate and inner layers in all experiments.

For all samples, the working fluids for the shell and core layer comprised $20 \mathrm{w} / \mathrm{v} \%$ PCL dissolved in $\mathrm{HAc}$ with predetermined quantities of GLP, $\mathrm{TiO}_{2} \mathrm{Ag}$ NPs or MNPs. The working fluid for the middle layer was $20 \mathrm{w} / \mathrm{v} \%$ EC dissolved in HAc. Mass ratios of GLP/PCL (shell layer), $\mathrm{TiO}_{2}-\mathrm{Ag} \mathrm{NP/PCL}$ (shell layer) and $\mathrm{MNP} / \mathrm{PCL}$ (core layer) were $10 \%, 10 \%$ and $2.5 \%$, respectively.

\subsection{Characterization}

Scanning electron microscopy (SEM) was used to observe the dimension, surface morphology and internal structure of the fabricated particles. For SEM observation, the samples were attached on the sample holder (a metallic stud) by double-side adhesive tapes for sputter coating. A thin layer of gold under vacuum (Ion Sputter MC1000, Hitachi, Japan) was deposited for $90 \mathrm{~s}$. 
SEM images were captured using a field emission scanning electron microscope (FE-SEM, FEI Quanta 650 FEG; Hillsboro, OR). The diameters of the samples were obtained using 740 particles from the SEM micrographs and analyzed using imageJ software (National Institute of Health).

An automated surface area analyzer (3H-2000PS2, Beishide Instrument Technology Co. Ltd., Beijing, China) was used to measure the specific surface area for the samples which had already been dried at $30^{\circ} \mathrm{C}$ for $2 \mathrm{~h}$. The pore volumes and pore size distributions were derived from the adsorption branches of the isotherms using the multipoint BJH (Barrett, Joyner, Halenda) method.

Fourier transform infrared (FTIR) spectroscopy was used to analyze sample composition. Pellets for FTIR were prepared by mixing $2 \mathrm{mg}$ of particles with $200 \mathrm{mg}$ of $\mathrm{KBr}$ powder by grinding and subsequently compressing the mixture into transparent pellets under the pressure of $12 \mathrm{MPa}$. The pellets were then scanned by FTIR (IR Affinity 1, Shimadzu, Japan), and the spectra were obtained at a resolution of $4 \mathrm{~cm}^{-1}$ ranging from 4000 to $500 \mathrm{~cm}^{-1}$. Each spectrum was obtained using 10 scans.

X-ray diffraction (XRD) was used to confirm the successful encapsulation of MNPs, GLP and $\mathrm{TiO}_{2}-\mathrm{Ag}$ NPs in samples, and spectra were measured with a diffractometer (X'pert PRO; PANalytical, the Netherlands) equipped with a standard $\mathrm{Cu} K \alpha$ radiation source $(\lambda=1.5405 \AA)$ and scanned within a $2 \theta$ range of $5-90^{\circ}$ at a step size of $0.026^{\circ}$. The operating voltage and current were $40 \mathrm{kV}$ and $40 \mathrm{~mA}$, respectively.

Magnetization curve of the samples was acquired using a vibration sample magnetometer (VSM Mini-CFM measurement system; Cryogenic Ltd., U.K.) at $300 \mathrm{~K}$ under a reciprocating 
altered magnetic field (-10 000 to $10000 \mathrm{Oe}$ ), and saturation magnetization was obtained from hysteresis loops.

Prussian blue staining was used to confirm the presence of iron in the YSPs. Briefly, $20 \mathrm{mg}$ of YSPs were incubated with $2 \%$ potassium ferrocyanide in $6 \%$ hydrochloric acid for 30 min, and then washed with deionized water and centrifuged for three times. The final product was observed.

Thermogravimetric (TGA, TA Q50, USA) analysis was performed for PCL, GLP, and porous YSPs. TGA was conducted under nitrogen atmosphere by heating the samples from 35 to $800{ }^{\circ} \mathrm{C}$ at a heating rate of $10^{\circ} \mathrm{C} / \mathrm{min}$. A differential scanning calorimeter (DSC, Q20, TA, USA) was used to study the thermal behavior of PCL, GLP, and porous yolk-shell particles. The DSC thermograms were obtained during heating from 35 to $800{ }^{\circ} \mathrm{C}$ at a rate of $10^{\circ} \mathrm{C} / \mathrm{min}$.

\subsection{In vitro Photothermal efficiency measurement}

The photothermal efficiency of DI water, DI water with YSPs (with MNP into the particles), and DI water with YSPs (without MNP into the particles) were tested. Firstly, $10 \mathrm{mg}$ of samples and $0.5 \mathrm{ml}$ of DI water were put introduced to a $1.5 \mathrm{ml}$ Eppendorf tube and vortexed for $30 \mathrm{~s}$ for complete and uniform mixing. The Eppendorf tubes were then fixed and exposed to an $808 \mathrm{~nm}$ laser (Power=3 W). Thermal graphs of the tested liquid were captured by a Fluke TI32 IR thermal camera. The temperature was calculated from the thermal graphs.

\subsection{GLP loading capacity (LC) and encapsulation efficiency(EE)}

LC and EE of GLP were determined according to previously mentioned methods. ${ }^{38}$ LC of GLP is the quantity of GLP encapsulated in the porous yolk-shell particles, and was calculated using 
$L C(\%)=\frac{\text { Amount of GLP encapsualted in the particles }(\mathrm{mg})}{\text { Weight of the particles }(\mathrm{mg})} \times 100 \%$

The EE of GLP in the porous yolk-shell particles was determined according to Eq. (2):

$$
E E(\%)=\frac{\text { Amount of GLP encapsulated in the particles }(\mathrm{mg})}{\text { Theoretical total amount of GLP }(\mathrm{mg})} \times 100 \%
$$

\subsection{In vitro GLP release}

Drug release tests were conducted both without and with laser irradiation $(3 \mathrm{~W})$ in vitro. This study involved placing $30 \mathrm{mg}$ of sample powder into a glass vial with $15 \mathrm{~mL} \mathrm{PBS}(\mathrm{pH}=7.4)$ and the vials were incubated at room temperature $\left(25^{\circ} \mathrm{C}\right)$ for $72 \mathrm{~h}$. At each specified time interval, 4 $\mathrm{mL}$ of supernatant was removed from the release medium and was replaced with an equal volume of fresh PBS. To determine the concentration of GLP, the collected supernatant was analyzed using a UV-2600 spectrophotometer (Shimadzu, Japan) at a wavelength of $221 \mathrm{~nm}$. The GLP release profile was subsequently drawn based on the quantity of encapsulated GLP over time. For each sample, experiments were performed in triplicate.

\subsection{Cell culture}

The L929 mouse fibroblast cells were cultured in 96-well plates containing MEM with 10 $\mathrm{v} / \mathrm{v} \%$ heat-inactivated fetal bovine serum (FBS, Gibco, USA) and $1 \%(\mathrm{v} / \mathrm{v})$ antibioticantimycotic at $37{ }^{\circ} \mathrm{C}$ in a humidified atmosphere of $5 \% \mathrm{CO}_{2}$.

\subsubsection{Cell morphology detection}

To clearly show the morphology, cells were incubated for $48 \mathrm{~h}$. After incubation, cell growth and morphology were observed by fluorescence imaging. The L929 cells were seeded into 6-well plates and then incubated with three various concentrations of GLP-loaded YSPs $(0.1,1$ and 5 $\mathrm{mg} / \mathrm{mL}$ GLP) for $48 \mathrm{~h}$. After incubation, cell growth and morphology were observed by 
fluorescence imaging. Briefly, cells were firstly fixed through $4 \%$ paraformaldehyde for $30 \mathrm{~min}$ and then treated with $0.1 \%$ Triton X-100 for 10 min to achieve permeabilization. Rhodaminephalloidin (20 min) and DAPI (5 min) with PBS washing in between were used to stain cell cytoskeleton and nuclei, respectively. Finally, cells were visualized using an inverted fluorescence microscope (Nikon, Eclipse Ti-S, Japan).

\subsubsection{Cck-8 assay}

Cell viability was assessed by Cell Counting Kit-8 (CCK-8). The L929 cells were seeded into 96-well plates and then incubated with three different concentrations of GLP-loaded YSPs $(0.1$, 1 and $5 \mathrm{mg} / \mathrm{mL}$ GLP) for $8 \mathrm{~h}, 24 \mathrm{~h}$ or $48 \mathrm{~h}$. The culture medium was then removed and the cells were rinsed three times with PBS. After washing, CCK-8 assays were carried out. In brief, $20 \mu \mathrm{L}$ of CCK-8 and $180 \mu \mathrm{L}$ of MEM were added into the wells and incubated at $37^{\circ} \mathrm{C}$ for $3 \mathrm{~h}$. Finally, the absorbance of each well was measured through a microplate reader (Multiskan GO, Thermo Fisher Scientific, USA) at a wavelength of $450 \mathrm{~nm}$. Cell viability was calculated using Eq.(3):

$$
\text { Cell viability }(\%)=\frac{A_{S}-A_{B}}{A_{C}-A_{B}} \times 100 \% \text { (3) }
$$

where $A_{s}, A_{C}$ and $A_{B}$ represent the absorbance of sample, control and blank groups, respectively.

\subsubsection{Live/dead assay}

The culture medium containing $\mathrm{H}_{2} \mathrm{O}_{2}$ was removed and the cells were washed with fresh MEM three times. A live/dead kit, which contains Calcein-AM and propidium iodide (PI) for live and dead cells, was used to counterstain the cells. Images were recorded under an inverted fluorescence microscope.

\subsubsection{ROS staining}


The L929 cells were cultured in 6-well plates for $24 \mathrm{~h}$ for fluorescent staining, or cultured in 96-hole plates for CCK-8 kit. The cells were washed with PBS and then incubated with three different concentrations of GLP-loaded YSPs $(0.1,1$ and $5 \mathrm{mg} / \mathrm{mL}$ GLP) for $72 \mathrm{~h}$. After being washed with MEM three times, MEM containing $3.2 \mathrm{mM} \mathrm{H}_{2} \mathrm{O}_{2}$ was then added to the wells and kept for $12 \mathrm{~h}$ after removing the solution. Then three different kinds of staining were conducted for visualization. The culture medium containing $\mathrm{H}_{2} \mathrm{O}_{2}$ was removed and the cells were washed with fresh MEM three times, and then incubated with DCFH-DA $\left(2^{\prime}, 7^{\prime}-\right.$ dichlorodihydrofluorescein diacetate) at $37{ }^{\circ} \mathrm{C}$ for $1 \mathrm{~h}$. After the last washing step, the treated cells were observed under an inverted fluorescence microscope and ImageJ software was used to quantitatively analyze fluorescence intensity.

\subsubsection{Cell scratch assay}

The cell scratch assay is a simple and low-cost method to evaluate the migration ability of cells in vitro. Briefly, L929 cells were seeded into 24 -well plates at an initial density of $2 \times 10^{5}$ cells/well and incubated at $37^{\circ} \mathrm{C}$ for $24 \mathrm{~h}$. With the help of a ruler, a sterile tip of $200 \mu \mathrm{L}$ pipette was then used to make two perpendicular scratches in each well and the intersection was close to the center of the well. After three washes with PBS, the cells were incubated with three various concentrations of GLP-loaded YSPs $(0.1,1$ and $5 \mathrm{mg} / \mathrm{mL} \mathrm{GLP})$ as well as serum-free medium. The distribution and quantity of cells in the vicinity of the intersection in each well were checked under a microscope and photos were taken out at $0,24,72$ and $120 \mathrm{~h}$, respectively.

\subsection{In vitro anti-bacterial test}


The anti-bacterial properties of GLP-loaded YSPs were firstly examined through an inhibition zone test according to the agar diffusion method. E. coli and $S$. aureus were selected as representatives of Gram-negative (G-) and Gram-positive $\left(\mathrm{G}^{+}\right)$bacteria, respectively. Briefly, 20 $\mathrm{mL}$ of Violet Red Bile Agar was poured into sterile petri dishes for $E$. coli plating while the same volume of Baird-Parker Agar was poured into other identical dishes for S. aureus plating. In addition, thin solid tablets of GLP-loaded YSPs with a diameter of $13 \mathrm{~mm}$ were prepared by compressing $50 \mathrm{mg}$ of the powder into pellets under a pressure of $12 \mathrm{MPa}$. After the plates have solidified, $100 \mu \mathrm{L}$ fresh E. coli and S. aureus suspension was spread on corresponding plates before the tablets were positioned on the center of the plates. Finally, the plates were incubated at $37^{\circ} \mathrm{C}$ for $24 \mathrm{~h}$. The diameter of the zone of each sample was measured by Image $\mathrm{J}$ software to investigate the anti-bacterial activities of GLP-loaded YSPs.

Secondly, to test the antibacterial effect of the YSPs in humid environment (liquid-solid interface), $200 \mu \mathrm{L}$ of $E$. coli and $S$. aureus suspensions with pre-determined mass ratio of YSPs $(0,1,5,20,50 \mathrm{mg} / \mathrm{ml})$ was spread on solidified culture medium which were made as previously mentioned. The plates were incubated at $37^{\circ} \mathrm{C}$ for $24 \mathrm{~h}$ and then taken out for the observation of the bacteria density.

Lastly, to test the antibacterial effect of the YSPs in liquid environment, pre-determined weight of YSPs $(0,1,5,20,50 \mathrm{mg} / \mathrm{ml})$ were put into $10 \mathrm{ml}$ of $E$. coli and $S$. aureus suspensions in $15 \mathrm{ml}$ glass tubes. The tubes were incubated at $37{ }^{\circ} \mathrm{C}$ for $24 \mathrm{~h}$ and the pictures of the tubes were taken for comparing the optical density, which indicated the relative amount of the bacteria in the tube.

\subsection{In vivo burn wound healing on c57 mice}

Firstly, a burn wound model was created on every mouse according to an established model ${ }^{39}$. The mice were anesthetized with Pentobarbital sodium. The hair on their back was shaved and 
completely removed by depilatory cream then washed by DI water. The circular flat face $(10 \mathrm{~mm}$ diameter) of the top of an electric soldering iron cylindrical bar (heated to $200{ }^{\circ} \mathrm{C}$ ), was applied for $2 \mathrm{~s}$ on the central position of the hair-free skin of the mouse with the weight of the mouse lying on the heated cylindrical bar. The wound was almost round and slightly larger than $10 \mathrm{~mm}$ in diameter and was used as a burn wound model for the in vivo experiments.

After $48 \mathrm{~h}$, the 18 mice were randomly divided into three groups with 6 mice in each of the following groups: control group, YSP group, Laser plus YSP group. For the treatment, $5 \mathrm{mg} / \mathrm{ml}$ YSP suspensions were made by mixing pre-weighted YSPs into 50\% glycerol aqueous solution, and the suspension were moderately vortexed to ensure that the YSPs were evenly distributed in the mixture. $1 \mathrm{ml}$ of $50 \%$ glycerol aqueous solution was applied to each mouse in the control group. $1 \mathrm{ml}$ of the YSP suspensions were uniformly applied to the burn region on the back of every mouse in YSP group and Laser plus YSP group. Low power laser (100 mW) was applied to each mouse in Laser plus YSP group after covering the burn with the YSP suspensions. Treatment was given once every two days and the mice were sacrificed and the skin of the wound area and the peripheral zone was harvested for the later analysis.

\subsection{Wound closure measurements}

Wound area was measured using the digital photographs of the wounds taken every 10 days throughout the study. The area was measured by tracing leading edge of the epithelial layer using ImageJ software.

\subsection{Histologic evaluation}

The harvested specimens (wound area and its peripheral zone) were immediately fixed in $10 \%$ neutral buffered formalin, dehydrated through an alcohol gradient, cleaned, and embedded in paraffin blocks. Histological sections $(7 \mu \mathrm{m}$-thick $)$ were prepared using a rotary microtome 
(Microm HM340E, Thermo Scientific, Waltham, USA) and stained with hematoxylin and eosin (HE). In addition, Masson trichrome staining was carried out according to standard procedures.

\subsection{Statistical analysis}

Data from over three independent experiments are reported, and statistical analysis was carried out with data from separate specimens. Results are expressed as means \pm standard deviation and checked by normality tests. Statistical analysis was performed using Origin software. Student's paired t-test was performed for comparison of data of paired samples and ANOVA was used for multiple group comparisons. A value of $\mathrm{p}<0.05$ was considered to be statistically significant. The significance level is expressed as $* \mathrm{p}<0.05$ or $* * \mathrm{p}<0.01$.

\section{RESULTS AND DISCUSSION}

\subsection{Particles fabrication}

The YSPs were synthesized using a tri-needle co-axial electrospray setup, as shown in Figure 1a. The mechanism of the tri-needle co-axial electrospray process has been discussed in detail in a previous study ${ }^{31}$. The fabricated tri-layered particles were collected using ethanol as nonsolvent ${ }^{6}$. The stable jetting mode achieved is shown in Figure $1 \mathrm{~b}$, however, the boundary between different liquids cannot be seen clearly due to the dark color of the GLP particles. The formation of the separated layers can be judged from the morphology and structure of the particles through scanning electron micrographs. A schematic illustration of the YSPs highlights the dispersion of $\mathrm{TiO}_{2}-\mathrm{Ag}$ and GLP in the porous shell and the magnetic particles $\left(\mathrm{Fe}_{3} \mathrm{O}_{4}\right)$ dispersed in the solid core (Figure 1c). 


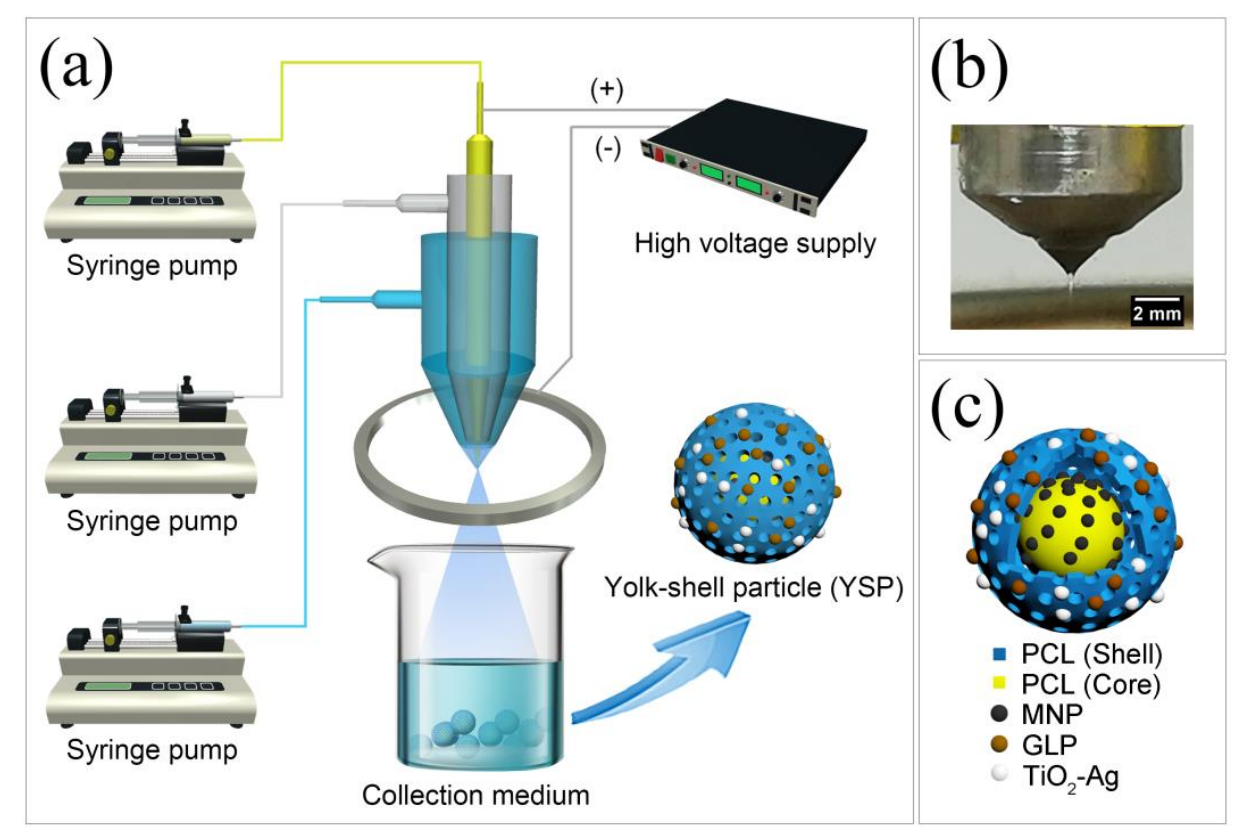

Figure 1. (a) Schematic illustrations of the tri-needle co-axial electrospraying system and collection system used in this study. (b) Digital graph of the stable jetting mode (under applied voltage of $12 \mathrm{kV}$, flow rates were $5.0,1.5,0.8 \mathrm{~mL} / \mathrm{h}$ for outer, middle and inner capillary). (c) A schematic illustration of the structure of the YSPs. The scattered black particles in the core represent $\mathrm{Fe} 3 \mathrm{O} 4$ nanoparticles, the scattered white and brown particles in the porous shell represent TiO2-Ag and GLP particles, respectively.

\subsection{Characterizations}

Figure 2a shows the SEM image of the YSPs; which demonstrate the production of particles of uniform size. Figure $2 b$ shows that the yielded YSPs have a uniform size distribution with a mean diameter of $16.25 \pm 3.64 \mu \mathrm{m}$. The size uniformity is critical to mass preparation and stable aqueous dispersion of YSPs. Large pores are clearly visible on the surface of the YSPS in Figure $2 \mathrm{c}$ whilst Figure $2 \mathrm{~d}$ exhibits the cross-section view of an YSP, which clearly highlights the three distinct layers of the YSPs (a shell, a solid core and a void space in between). 

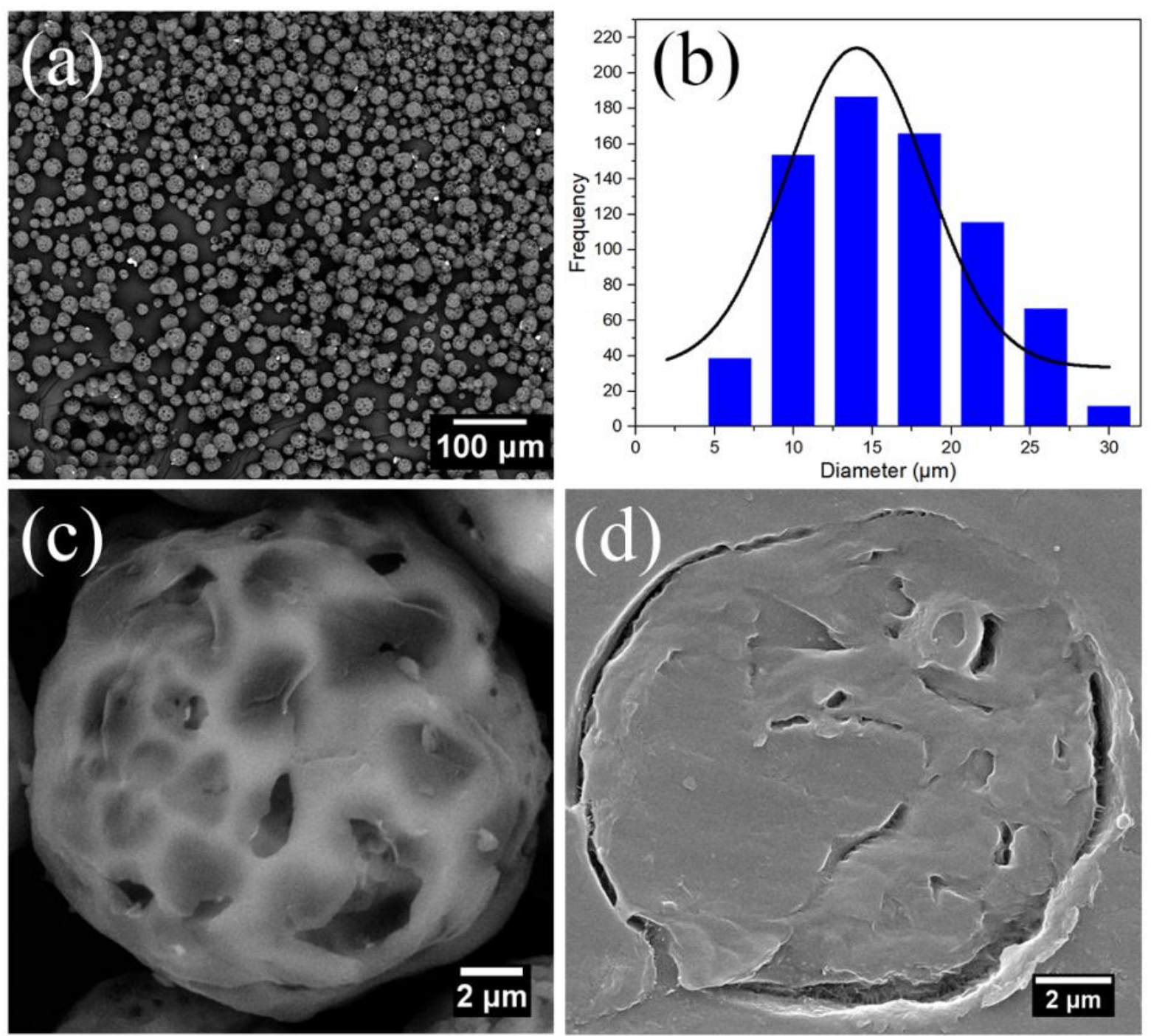

Figure 2. (a) Electron micrograph of YSPs. (b) Size distribution of the YSPs. (c) Electron micrograph of one of the YSPs of high magnification. (d) Cross-sectional electron micrograph of microsphere embedded in epoxy resin.

The BET method is used to measure and analyze the specific surface area and pore size distribution of porous materials. Figure 3a shows a $\mathrm{N}_{2}$ adsorption-desorption isotherm of YSPs, revealing that the engineered YSPs follow a typical Type III adsorption-desorption mechanism due to the relatively weak interactions between YSPs and $\mathrm{N}_{2}$ (according to the IUPAC 
classification ${ }^{40}$ ). Figure $3 b$ exhibits the pore size distribution curve of YSPs (mainly in a wide range from 2.0 to $20.0 \mathrm{~nm}$ ), which shows a main characteristic peak at around $2.6 \mathrm{~nm}$ and a side peak at about $3.2 \mathrm{~nm}$. This indicates that mesopores occupy a dominant position in the pore volume of YSPs.
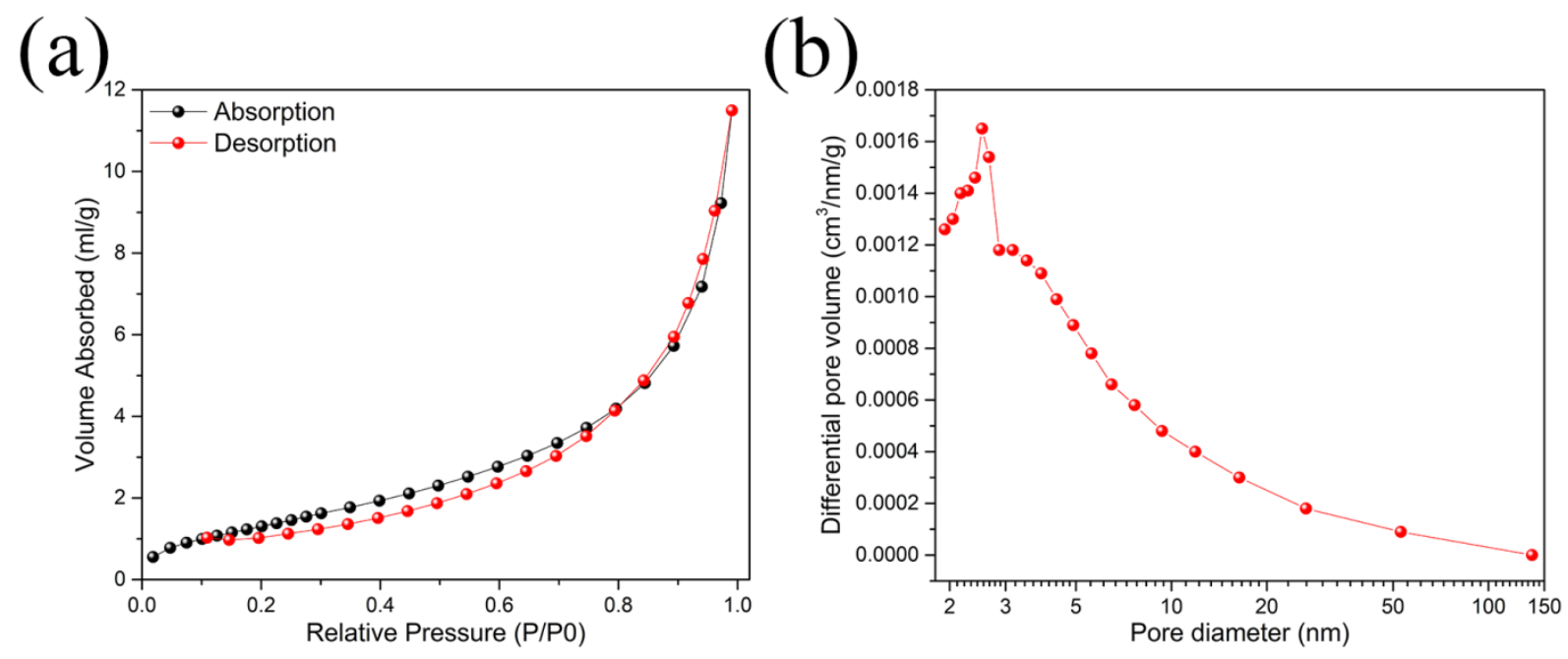

Figure 3. N2 adsorption-desorption isotherms (a) and pore size distribution curves (b) of YSPs.

Figure 4 shows the results of the chemical composition of the YSPs. FTIR spectroscopy is performed to study the chemical composition of materials and thus confirms the successful preparation of products. Figure 4a displays the FTIR spectra of pure GLP, $\mathrm{TiO}_{2}-\mathrm{Ag}$, pure MNPs, pure PCL and YSPs in the range from 4000 to $500 \mathrm{~cm}^{-1}$ region. For GLP, multiple characteristic peaks appear at 3385, 2916, 1637 and $1418 \mathrm{~cm}^{-1}$, which can be assigned to -OH stretching, C-H stretching, asymmetrical $\mathrm{COO}^{-1}$ and symmetrical $\mathrm{COO}^{-1}$ stretching, respectively ${ }^{41}$. A series of peaks for $\mathrm{TiO}_{2}-\mathrm{Ag}$ at about $540 \mathrm{~cm}^{-1}$ represent the stretching vibration for Ti-O, Ag-O and Ti-OTi bonds ${ }^{42}$. For MNPs, a characteristic peak at $583 \mathrm{~cm}^{-1}$ indicates the presence of Fe-O bands ${ }^{43}$. In addition, peaks at 2945,2875 and $1746 \mathrm{~cm}^{-1}$ belong to PCL are associated with $\mathrm{CH}_{2}$ asymmetric and symmetric stretching as well as $\mathrm{C}=\mathrm{O}$ stretching, respectively ${ }^{44}$. The corresponding characteristic peaks of GLP are not quite obvious in the final YSP sample, which 
may be attributable to the excellent encapsulation of GLP in the YSPs, similar to what has been reported previously ${ }^{45}$. However, all other aforementioned peaks all appear in the YSP sample, affirming the effective engineering of YSPs without chemical interactions.

(a)

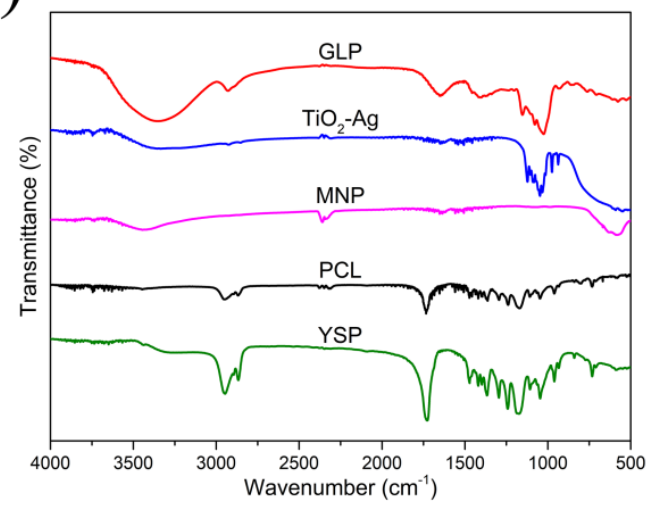

(c)

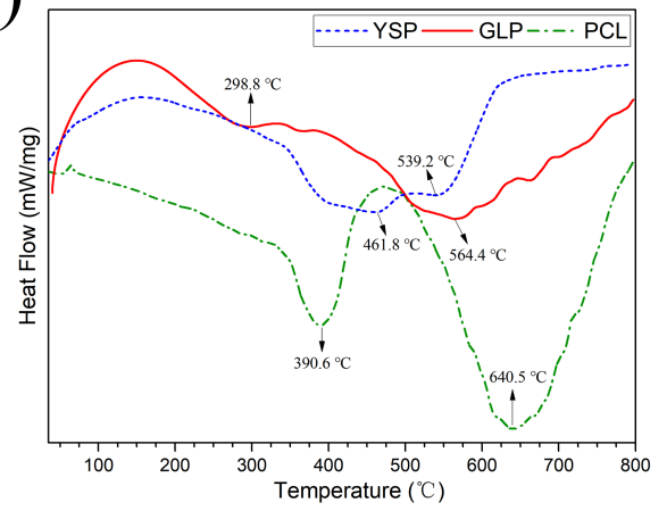

(b)

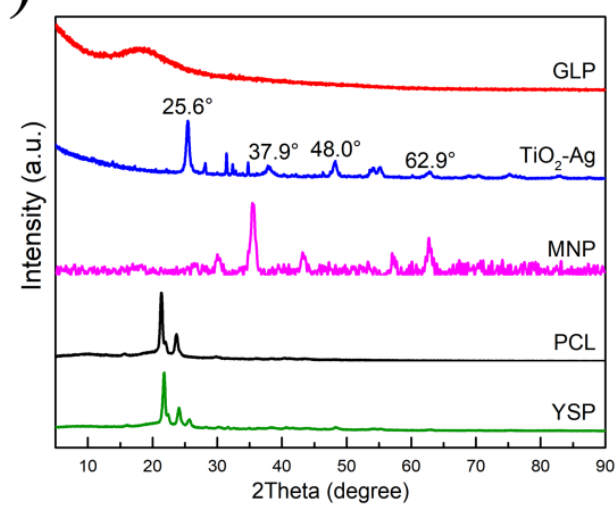

(d)

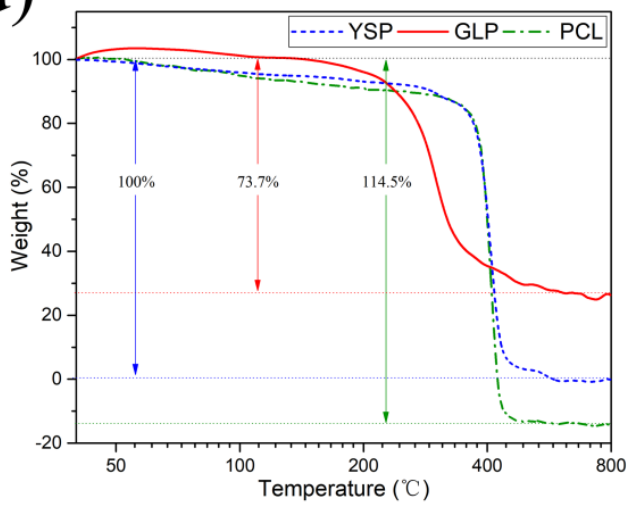

Figure 4. FTIR spectra (a), XRD spectra (b), DSC curve (c) and TGA curve (d) of the YSPs.

XRD technique was used for determining the crystalline structure of materials. The XRD patterns of pure GLP, $\mathrm{TiO}_{2}-\mathrm{Ag}$, pure MNPs, pure PCL and YSPs are shown in Figure 4b. Broad peaks are shown in the pattern of GLP, highlighting that it is present in a non-crystalline form ${ }^{46}$. For $\mathrm{TiO}_{2}-\mathrm{Ag}$, the pattern shows five distinct peaks at $2 \theta=25.6^{\circ}, 37.9^{\circ}, 48.0^{\circ}, 54.1^{\circ}$ and $62.9^{\circ}$ indexed to 101, 004, 200, 105 and 204 planes, respectively; mimicking previously reported values for pure $\mathrm{TiO}_{2}{ }^{47}$. For MNPs, there are five characteristic peaks at $2 \theta=30.1^{\circ}, 35.5^{\circ}, 43.2^{\circ}$, 
$57.0^{\circ}$ and $62.6^{\circ}$, corresponding to $220,311,400,511$ and 440 planes, respectively, which are compatible with the standard values in JCPDS card No. 19-062948. Two significant peaks are present between $20.0^{\circ}$ and $25.0^{\circ}$ emphasizing the semi-crystalline features of $\mathrm{PCL}^{49}$. The pattern of YSPs is similar to the one of PCL since only two characteristic peaks belonging to PCL are clearly observed, and the absence of other peaks is due to the low content of GLP, $\mathrm{TiO}_{2}-\mathrm{Ag}$ and MNPs.

Figure $4 \mathrm{c}$ shows the DSC thermograms of pure PCL, pure GLP and YSPs. For pure PCL, the curve exhibits two exothermic peaks at $390.6{ }^{\circ} \mathrm{C}$ and $640.5{ }^{\circ} \mathrm{C}$. For GLP, there are two characteristic peaks at $298.8{ }^{\circ} \mathrm{C}$ and $539.2{ }^{\circ} \mathrm{C}$. Furthermore, the curve of YSPs contains two sharp peaks at $461.8^{\circ} \mathrm{C}$ and $564.4^{\circ} \mathrm{C}$.

TGA is a technique used to assess the thermal stability of materials over time using a constant heating rate. The TGA results are plotted in Figure 4d, showing the changes in weight loss of GLP, PCL and YSPs, respectively. Compared to other two samples, the weight of the GLP sample was increasing before $60{ }^{\circ} \mathrm{C}$ due to the hydrophilic nature of GLP. At $160{ }^{\circ} \mathrm{C}$, the curve starts to decrease significantly, and eventually stops at about $600{ }^{\circ} \mathrm{C}$ with a $26.3 \%$ residue, which reveals one-step degradation behavior. In contrast, the PCL sample began to slightly degrade at an earlier temperature, and most of the degradation ( $79 \%)$ was completed between 350 and $450{ }^{\circ} \mathrm{C}$, which is consistent with a previously reported result ${ }^{31}$. Similar characteristics of degradation are seen with the YSPs, since YSPs are mainly composed of PCL. In conclusion, YSPs acting as carriers of GLP have a delayed main degradation time relative to the active pharmaceutical ingredient, which can help the latter to function more effectively.

The VSM measurement is used to study the magnetic properties of appropriate materials using a vibrating-sample magnetometer. Figure 5a shows the hysteresis loop for MNP-loaded YSPs; 
exhibiting superparamagnetic behavior at room temperature with a saturation magnetization value of $0.058 \mathrm{emu} / \mathrm{g}$.

Targeted transport of drug-loaded particles could be achieved by applying an external magnetic field based on the magnetic properties. Amalorpava et al have also shown that the properties can be strengthened effectively by increasing the magnetic content ${ }^{50}$. Figure $5 \mathrm{~b}$ shows the pictures of the YSPs without MNPs (I) and with MNPs (II) in the core after staining by potassium ferrocyanide. The stained sample of inset (b) (blue) indicates the successful encapsulation of MNPs in the YSPs. ${ }^{51}$

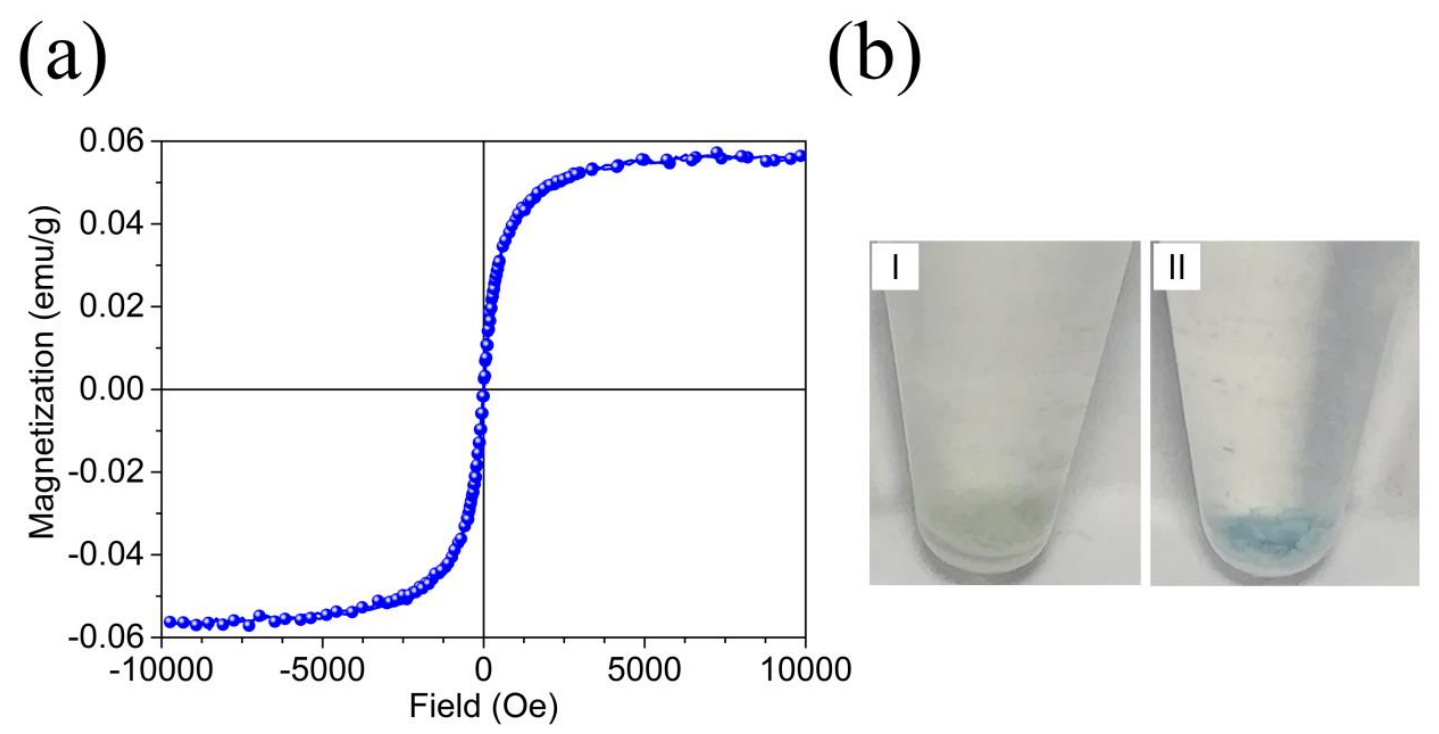

Figure 5. (a) Magnetic hysteresis loops of YSPs. (b) YSPs without MNP (I) and with MNP (II) stained by potassium ferrocyanide.

\subsection{In vitro photothermal effect}

The in vitro photothermal effect of the YSPs was evaluated by comparing the peak temperatures of the sample EP tubes at determined time points. Since the silver nanoparticles in $\mathrm{TiO}_{2}-\mathrm{Ag}$ particles also possess photothermal effects ${ }^{52}$, the YSP samples without MNPs were also 
tested to assess the photothermal effects caused by the silver nanoparticles and MNPs. PBS was tested without any particulate samples as the control group. Figure $6 \mathrm{a}$ and Figure $6 \mathrm{~b}$ shows the thermal graphs and temperature rise curves of the three groups. From the thermal graphs and the temperature rise curves, the existing silver nanoparticles only have slight photothermal effect (Figure 6a, row 2). While the YSP samples with MNP group have remarkable photothermal effect and the final temperature reached $71{ }^{\circ} \mathrm{C}$, which was much higher than the YSP samples without MNP group $\left(41.7^{\circ} \mathrm{C}\right)$ and the PBS group $\left(37.5^{\circ} \mathrm{C}\right)$. This test confirmed that the main photothermal agent in the YSPs are the MNPs rather than the silver nanoparticles, and that the MNP can generate heat by photothermal conversion under laser irradiation. The temperature spectra of the thermal graphs of the EP tubes also indicated that the YSPs are difficult to uniformly disperse in the PBS, so a more suitable delivery medium should be selected when the YSPs are used in vivo.

(a)

1)

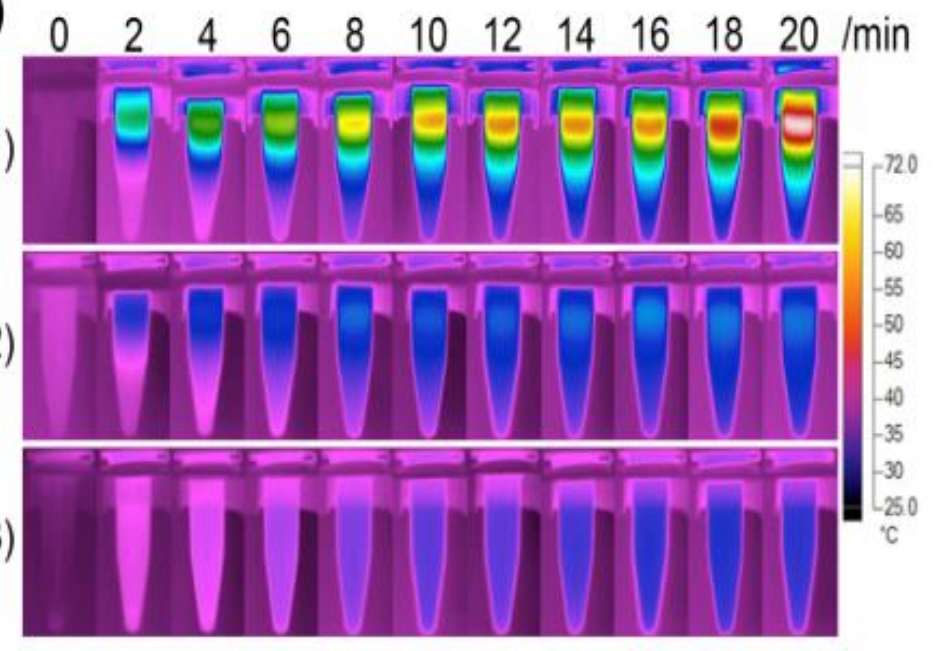

(b)

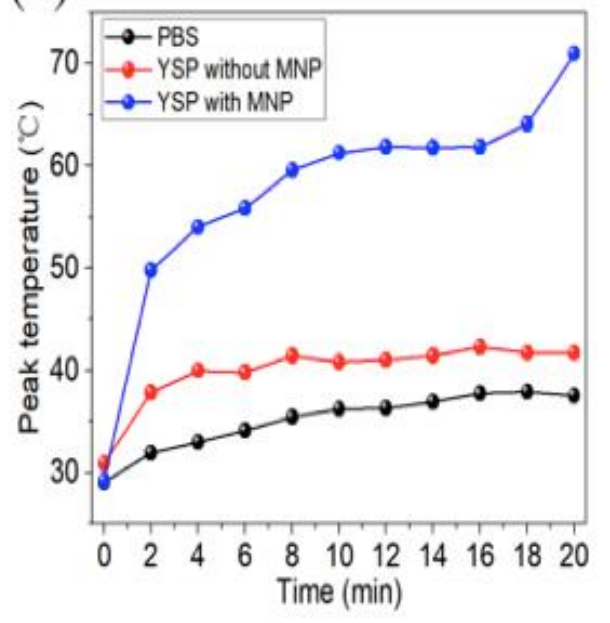


Figure 6. (a) Thermal graphs of the sample EP tubes of the (1) YSP with MNP and $\mathrm{TiO}_{2}-\mathrm{Ag}$ group, (2) YSP containing $\mathrm{TiO}_{2}-\mathrm{Ag}$ without MNP group, and (3) PBS group at determined time points. (b) Peak temperature rise curves of the sample EP tubes of three groups.

\subsection{In vitro drug release}

The encapsulation efficiency and the loading capacity of GLP into YSP was $93.43 \pm 0.38 \%$ and $6.85 \pm 0.03 \%$, respectively. Figure 7 a shows the release profile of the encapsulated GLP in the YSPs measured at room temperature $\left(25^{\circ} \mathrm{C}\right)$. In the first 30 mins a burst release of GLP can be seen with over $50 \%$ being released, emphasizing the special structure of the YSPs can ensure rapid release of the encapsulated GLP from the porous shell. Here after, GLP reease slows with over $70 \%$ being released after $4 \mathrm{~h}$. a third stage in the release profile shows GLP release being sustained at a relatively low release rate. Figure $7 \mathrm{~b}$ shows a comparison of the release profile of GLP for a duration of 2 hours. During the first 30 mins, the amounts of released GLP were almost the same. This may be due to the fast heat exchange between the release medium and the surrounding air. Because of the accumulation of the heat generated by the photothermal effect, the laser group presented faster GLP release rate.

(a)

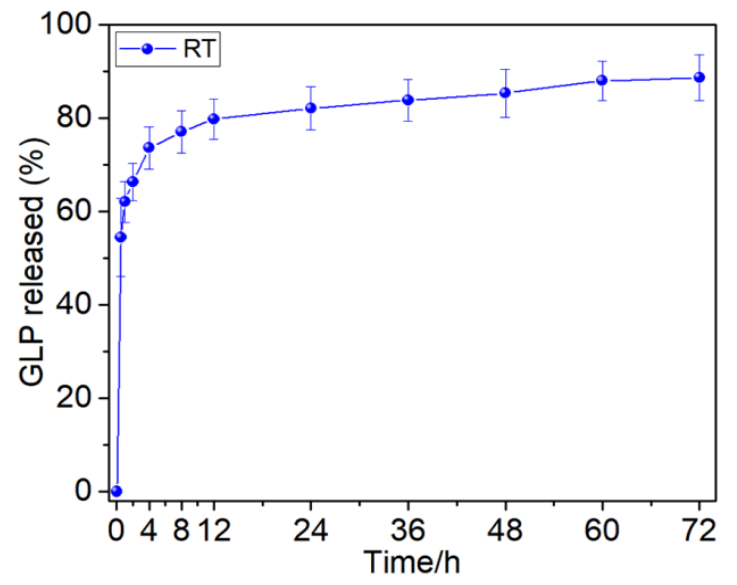

(b)

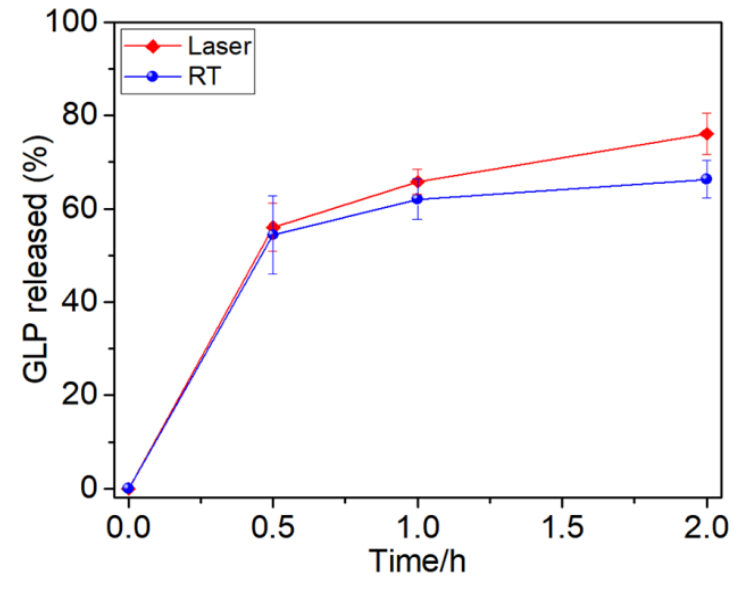


Figure 7. (a) Time-dependent release kinetics of GLP without laser irradiation for 3 days. (b) Time-dependent release kinetics of GLP with and without laser irradiation for 2 hours.

\subsection{Biocompatibility test}

Cell morphology was assessed by fluorescence microscopy after cells were counterstained with DAPI and Rhodamine-Phalloidin for DNA in blue and F-actin in red, respectively. For GLP-loaded YSPs, three specific concentrations $(0.1,1$ and $5 \mathrm{mg} / \mathrm{mL}$ GLP) were processed in this way, and merged images are shown in Figure 8a. In contrast with the control group, all three GLP-loaded YSP groups promoted cell growth and cell adhesion; the higher the concentration, the more apparent these effects highlighting the lack of toxicity.

(a)

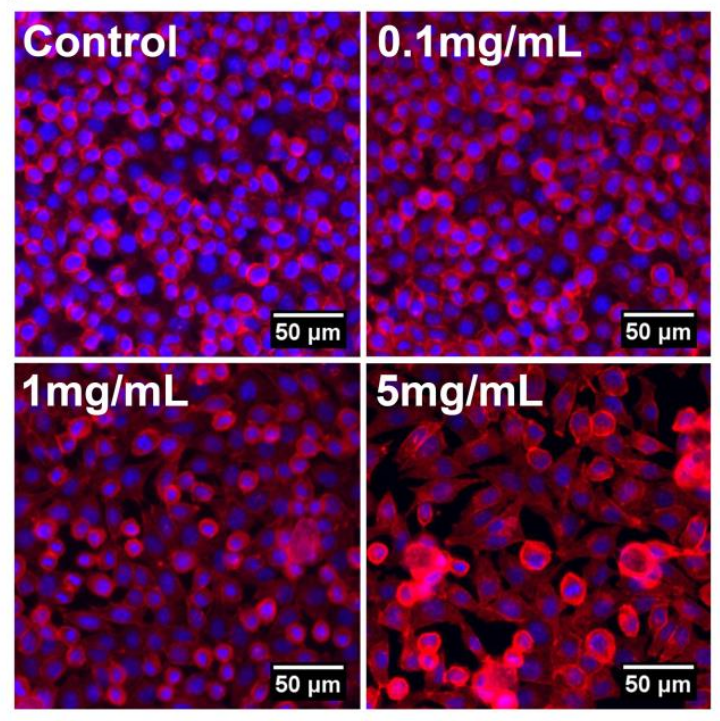

(b)

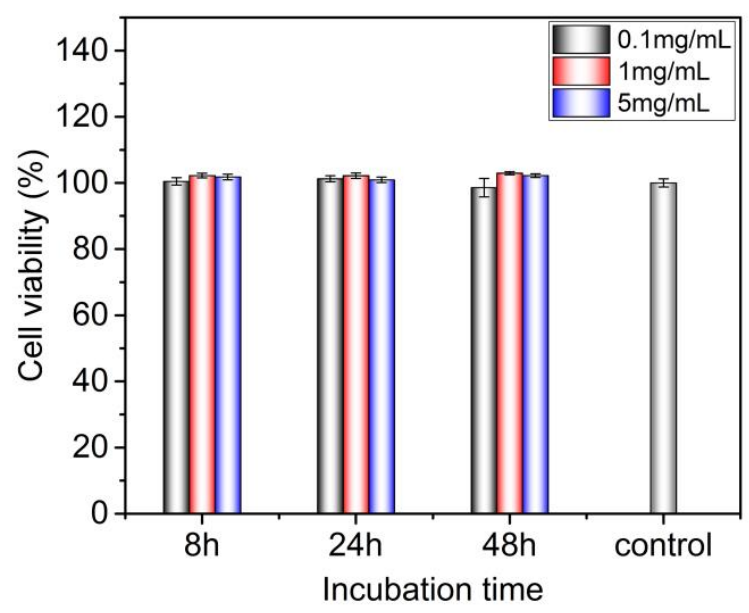

Figure 8. (a) Cells incubated with YSPs at varying concentrations in culture medium over $48 \mathrm{~h}$. Figures are merged fluorescence micrographs of nuclei stained with DAPI (blue) and cytoskeleton stained with Rhodamine-phalloidin (red). (b) Cell viability with predetermined quantities of YSPs in culture medium over designated times. 
Cell viability after material treatment is an important indicator to measure the biocompatibility of materials. In this study, the effect of GLP-loaded YSPs with three different concentrations $(0.1,1$ and $5 \mathrm{mg} / \mathrm{mL}$ GLP) on cell viability was evaluated using CCK-8 assay. Three designated times $(8,24$ and $48 \mathrm{~h})$ were applied and the viability was set to $100 \%$ in the control groups. The results in Figure $8 \mathrm{~b}$ specify that there is no significant difference in cell viability among the three groups compared with the control groups during observation, which indicates YSPs have negligible toxicity and favorable cytocompatibility.

\subsection{In vitro anti-oxidant effect}

The effect of therapy of GLP-loaded YSPs on $\mathrm{H}_{2} \mathrm{O}_{2}$-treated L929 cell viability was further investigated through an anti-oxidant effect test. DCFH-DA, the most common probe for revealing intracellular $\mathrm{H}_{2} \mathrm{O}_{2}$ and oxidative stress ${ }^{53}$, was used to show ROS levels after treatment with three different concentrations of GLP-loaded YSPs $(0.1,1$ and $5 \mathrm{mg} / \mathrm{mL}$ GLP). Typical images are shown in Figure 9a. Compared to normal cells that contain almost no labeling, fluorescence intensity was significantly increased in $\mathrm{H}_{2} \mathrm{O}_{2}$-treated cells, which exhibited a high intracellular ROS level. However, the intensity was reduced considerably following the addition of GLP-loaded YSPs. Figure 9d shows fluorescence intensity quantitative analysis results, which display the dose-dependent ROS scavenging ability of GLP-loaded YSPs. The above results support that GLP-loaded YSPs have anti-oxidant effects and can be used for ROS protection, which complement the results of the live/dead assay (Figure 9c).

Figure $9 \mathrm{~b}$ shows the cell morphology of the cells pre-treated with YSPs loaded MEM after treated by $\mathrm{H}_{2} \mathrm{O}_{2}$. From the figure, the area of the cell membrane has clearly diminished. It has even reduced to the same size of the nucleus, when the cells were co-cultured without YSPs 
$\left(\mathrm{H}_{2} \mathrm{O}_{2}\right)$ or only with low concentration of YSPs $(0.1 \mathrm{mg} / \mathrm{ml})$. When the cells were co-cultured with YSPs with a concentration of $1 \mathrm{mg} / \mathrm{ml}$ or $5 \mathrm{mg} / \mathrm{ml}$, the area of the cell membrane only changed slightly, indicating that the cells could be protected by the bioactive released from YSPs.

The treatment effect of GLP-loaded YSPs on the viability of $\mathrm{H}_{2} \mathrm{O}_{2}$-treated L929 cells was examined by the live/dead assay, as shown in Figure 9c. Through fluorescence microscopy, live cells appear green due to Calcein-AM staining and dead cells are shown in red caused by PI staining. Reactive oxygen species (ROS) can cause cellular responses (such as apoptosis) in reaction to oxidative stress, and $\mathrm{H}_{2} \mathrm{O}_{2}$ was selected as the representative of ROS to prepare oxidatively damaged cells. Compared with the control group, the death rate of the $\mathrm{H}_{2} \mathrm{O}_{2}$ group increased significantly after being treated by $\mathrm{H}_{2} \mathrm{O}_{2}$. Three different concentrations of GLP-loaded YSPs $(0.1,1$ and $5 \mathrm{mg} / \mathrm{mL}$ GLP) were then used to deal with the damaged cells. The uniform distribution of red and green fluorescence is seen in the low concentration group of GLP (0.1 $\mathrm{mg} / \mathrm{ml}$ ), designating GLP improves cell viability. Furthermore, the intensity of green fluorescence rose considerably in the intermediate $(1 \mathrm{mg} / \mathrm{ml})$ and high $(5 \mathrm{mg} / \mathrm{ml})$ concentration groups. Therefore, reactivation of cell viability is observed and positive correlation with the concentrations was determined. The results verify that GLP-loaded YSPs can provide the therapeutic effect for $\mathrm{H}_{2} \mathrm{O}_{2}$-damaged cells, suggesting that GLP-loaded YSPs has the potential to eliminate ROS damage to the human body.

Moreover, quantitative analysis of cell viability was carried out using CCK-8 assay to evaluate the effect of intracellular ROS levels on it (Figure 9e). After $\mathrm{H}_{2} \mathrm{O}_{2}$ treatment, cell viability dropped dramatically to $32.7 \pm 1.3 \%$ as cells were oxidatively damaged. As mentioned above, ROS levels declined dramatically due to the incorporation of GLP-loaded YSPs. In the same 
period, cell viability rose visibly to $67.2 \pm 1.2 \%$ and $80.8 \pm 3.0 \%$ in the low and medium concentration groups, respectively, while high concentration group was back to $98.3 \pm 1.8 \%$, approximately the same level as the figure of the control group. The results disclose that GLPloaded YSPs can improve cell viability, and there is a negative correlation between intracellular ROS levels and the viability.

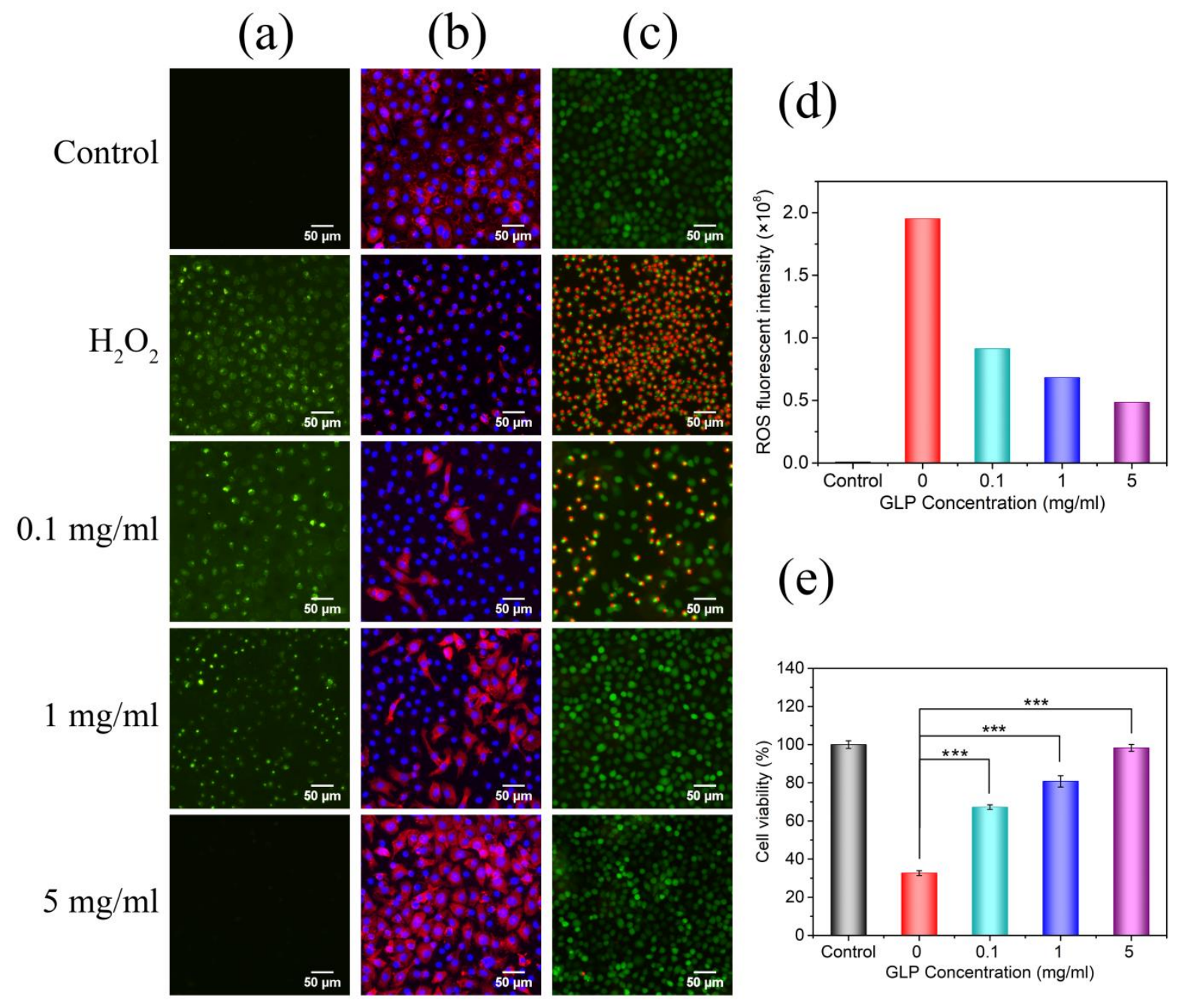

Figure 9. Anti-oxidant effect. Cells treated with varying concentrations of YSPs for $72 \mathrm{~h}$ and $\mathrm{H}_{2} \mathrm{O}_{2}$ treated for $12 \mathrm{~h}$, then stained with ROS probe (DCFH-DA) (Figure (a)), DAPI and Rhodamine-phalloidin (Figure (b)) and live-dead assay (Figure (c)). (d) is the ROS fluorescent 
intensity calculated from Figure (a). (e) is the cell viability with varying quantities of YSPs after $\mathrm{H}_{2} \mathrm{O}_{2}$ treatment.

\subsection{Cell scratch assay}

The in vitro cell scratch assay was performed to simulate the therapy effects of GLP-loaded YSPs on wound healing. The results are shown in Figure 10. For the control group and the low concentration group $(0.1 \mathrm{mg} / \mathrm{ml})$, cell adhesion was relatively weak (the cells in the nonscratched region only filled less than half of the area, which indicated that part of the cells were washed away during the cell culture process), and only very few cells migrated to the crossshaped area. For the middle concentration group $(1 \mathrm{mg} / \mathrm{ml})$, cell density in the non-scratched region was obviously higher than the control group and the low concentration group with cell migration starting in $72 \mathrm{~h}$ then booming after $120 \mathrm{~h}$ (almost filled up the cross-shaped area). For the high concentration group $(5 \mathrm{mg} / \mathrm{ml})$, cell adhesion in the non-scratched area was much stronger than all the other groups, which indicated that the extract of the YSPs could potentially improve the adhesion of the cells; mainly caused by the nutrients provided by the dissolved GLP in the culture medium. However, the cell density in the scratched area is lower than the middle concentration group (1 mg/ml), which may be due to the excessive content of YSPs covering the cells and hindering the migration of the cells. By comparing the results of the middle and high concentration groups, the YSPs mainly enhanced the proliferation and adhesion of the cells, but slightly enhanced the migration of the cells. Since cell proliferation and adhesion is important for skin wound healing process, these results demonstrated from one side that the YSPs have the potential effect in skin wound healing, but the mass ratio of the components need to be further considered to achieve better therapeutic effect. In addition, the micrographs also show that the YSPs at proper concentrations can enhance cell proliferation of the L929 cells, but no obvious 
cell migration activity could be observed, which suggests that the extractum of the YSPs mainly influence the proliferation and adhesion of cells but have limited functionality to enhance migration (motion) of L929 cell.

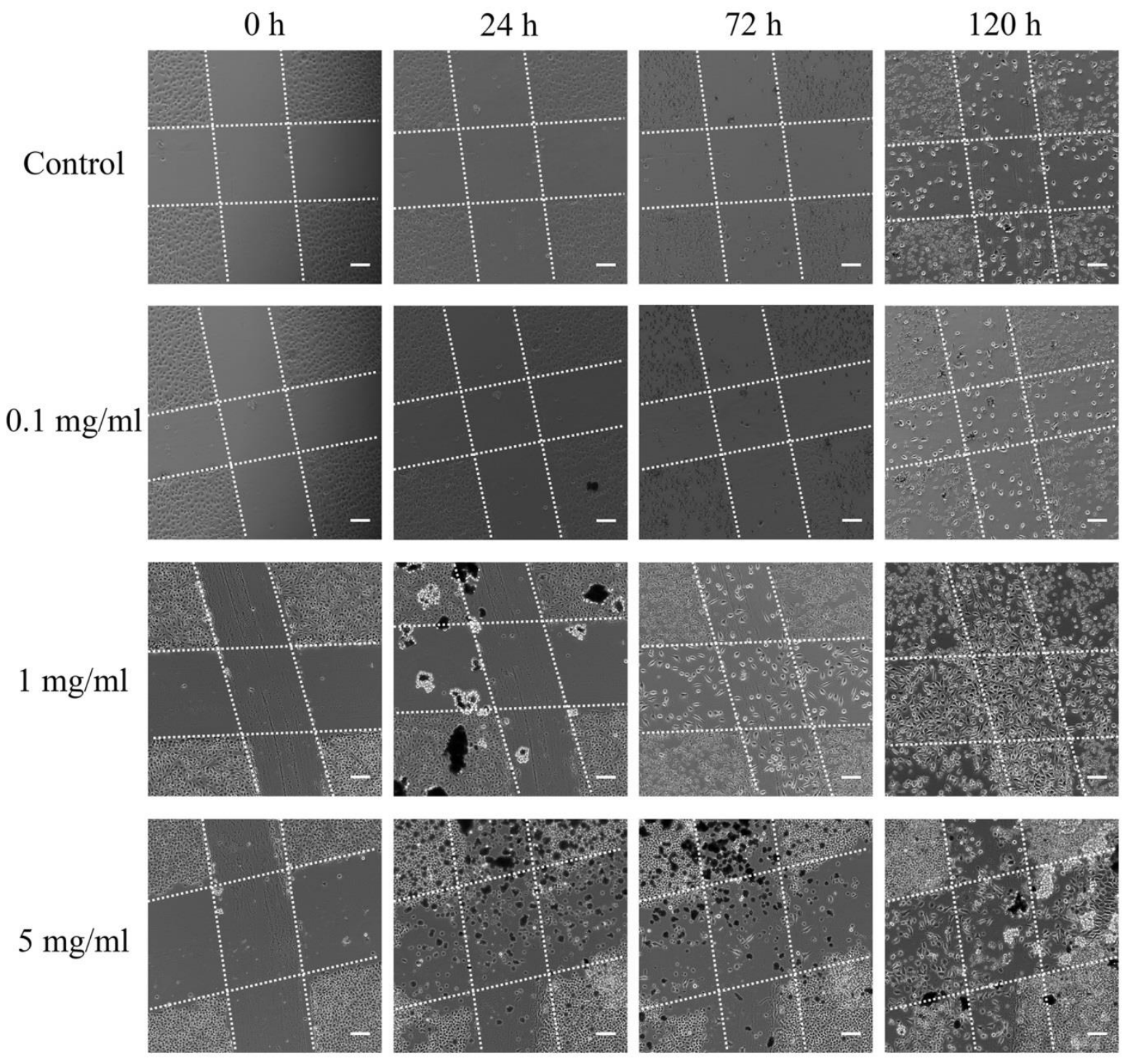

Figure 10. Optical micrographs of cell scratch assay. The dash lines were added to show the boundary of the cross-shaped scratched region created by the tip of a $200 \mu \mathrm{l}$ pipette. All the scale bars represent $100 \mu \mathrm{m}$. The dark spots and big clusters distributed on some micrographs are the residual YSPs. 


\subsection{In vitro anti-bacterial effect}

The anti-bacterial properties of GLP-loaded YSPs were examined by means of the agar diffusion method over a $24 \mathrm{~h}$ period. E. coli and S. aureus were chosen as models for Gramnegative (G-) and Gram-positive (G+) bacteria, respectively. After $24 \mathrm{~h}$ incubation, the inhibition zones of the tablets are shown in Figure 11a and 11d. Small inhibition zones (with a zone diameter of $14.48 \pm 0.39 \mathrm{~mm}$ in Figure 11a and $16.30 \pm 0.17 \mathrm{~mm}$ in Figure 11d) prove that GLPloaded YSPs can only slightly restrain bacterial growth and infection on solid surface. Figure $11 \mathrm{~b}$ and $11 \mathrm{e}$ show that the YSPs had good anti-bacterial effect when the concentration of YSPs increased to $50 \mathrm{mg} / \mathrm{ml}$ in the bacteria solution especially for $S$. aureus.

Figure 11c and 11f show that with the increase of the concentration of the YSPs in bacteria solution, the black texture (full of printed letter "E") behind the glass tubes can be seen more and more clearly, which indicated a reduction in bacteria.

To sum up, the results above demonstrated that the YSPs show stronger anti-bacterial effect in liquid condition than in dry state, which indicated that the anti-bacterial process of the YSPs must have water involved because the incorporated anti-bacterial component $\mathrm{TiO}_{2}-\mathrm{Ag}$ particles show better anti-bacterial effect in water condition. This result confirmed that the YSPs should be used in the form of liquid form particle suspension when served as the anti-bacteria agents in wound healing process, which is due to the incorporation of water enhanced the interaction between the $\mathrm{TiO}_{2}-\mathrm{Ag}$ nanoparticles and bacteria. 

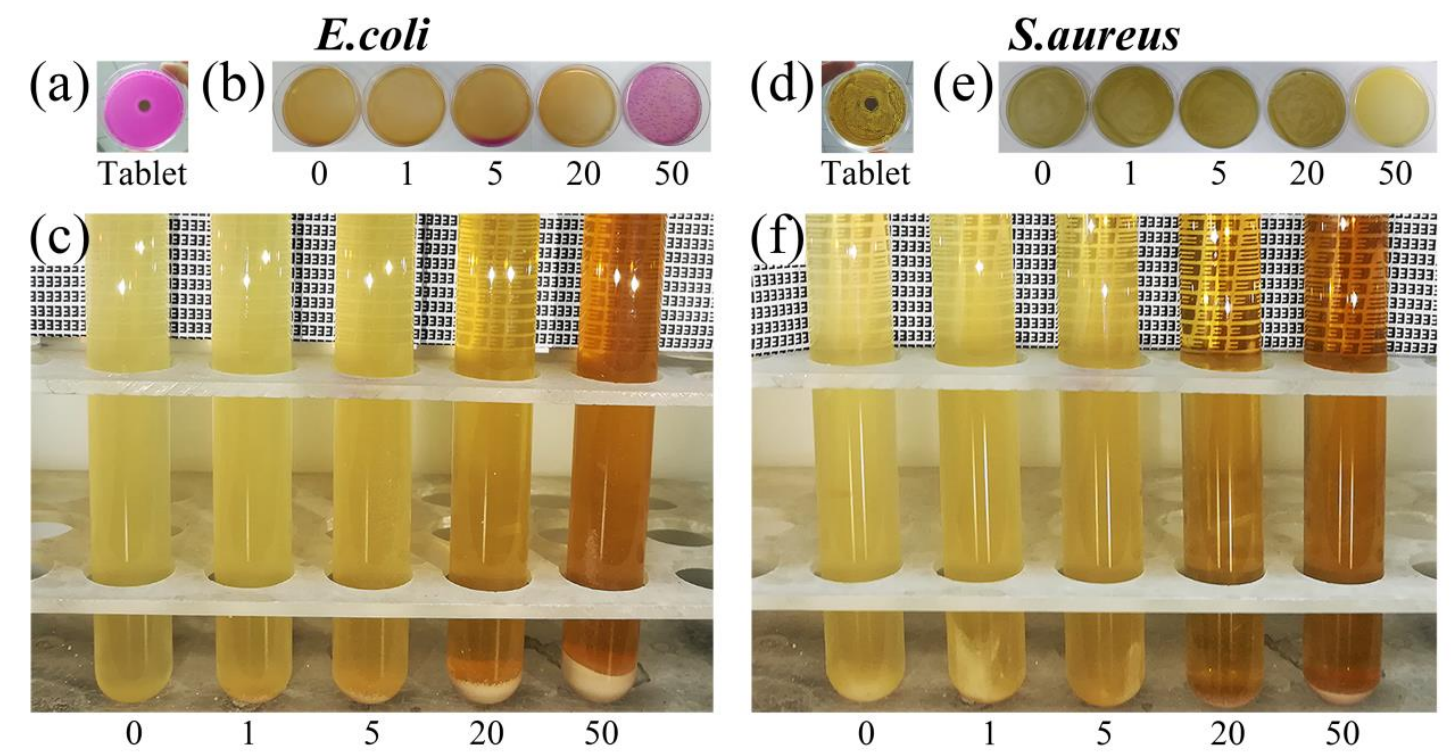

Figure 11. Anti-bacterial effect of the YSPs. Inhibition zone test of the YSPs (a and d), and bacteria solution with varying concentration of YSPs coated and cultured on the solid culture medium ( $b$ and e) and cultured in glass tubes (c and f). (The bacteria are E.coli (for a-c) and S.aureus (for $\mathrm{d}-\mathrm{f})$ ). The unit is $\mathrm{mg} / \mathrm{ml}$ in figures $\mathrm{b}$, c, e and $\mathrm{f}$.

\subsection{Wound healing.}

For the therapy, the mice with burns were randomly divided into three groups (control group, YSP group and the Laser plus YSP group). For the control group, $1 \mathrm{ml}$ of $50 \%$ glycerol aqueous solution was applied to the burn region of each mouse. For the YSP and Laser plus YSP group (the concentration of the YSP suspension is $5 \mathrm{mg} / \mathrm{ml}$ ), $1 \mathrm{ml}$ of the YSP suspensions was uniformly applied to the burn region on the back of every mouse. Low power laser (100 $\mathrm{mW})$ was applied to each mouse in the Laser plus YSP group following this. Treatment was given every two days and the mice were sacrificed and the skin of the wound area and the peripheral zone was harvested for the later analysis. 
As demonstrated in Figure 12a and 12b, the YSPs suspension can moderately increase the body temperature of the mice even at a low concentration. The body temperature on the back of the mice increased from about $38{ }^{\circ} \mathrm{C}$ to $45^{\circ} \mathrm{C}$ through 10 minutes' of laser irradiation and the temperature fluctuates around $45^{\circ} \mathrm{C}$ which could potentially avoid the secondary injury caused by the laser burns. The trend of the temperature is consistent with the in vitro experiments; a plateau occurs after a rapid temperature increase at the first period.

(a)
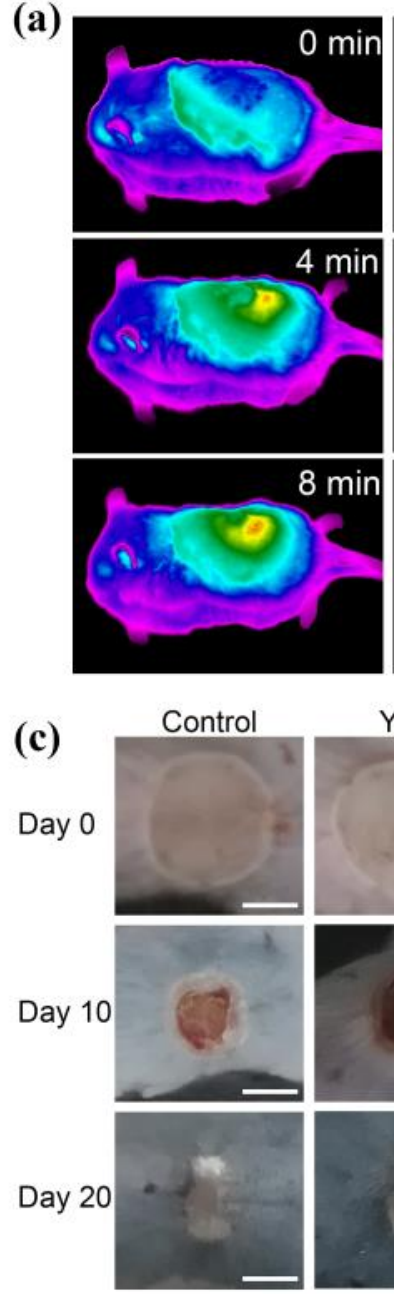
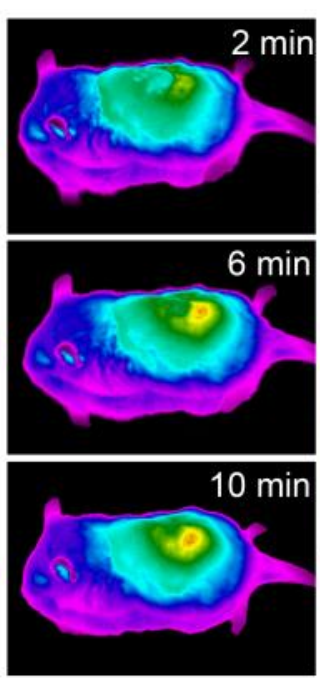

YSP
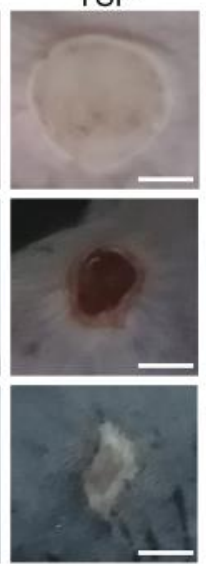
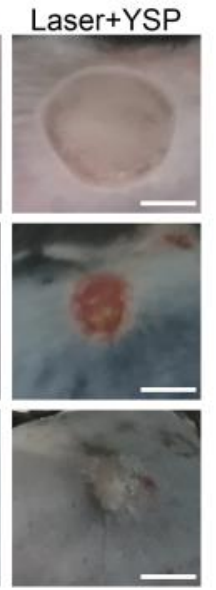

(b)

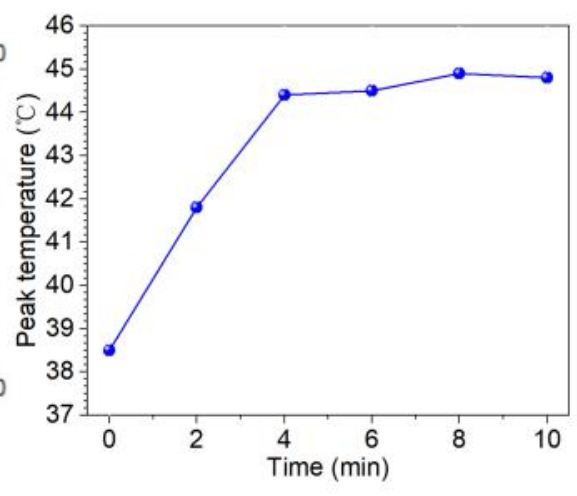

(d)

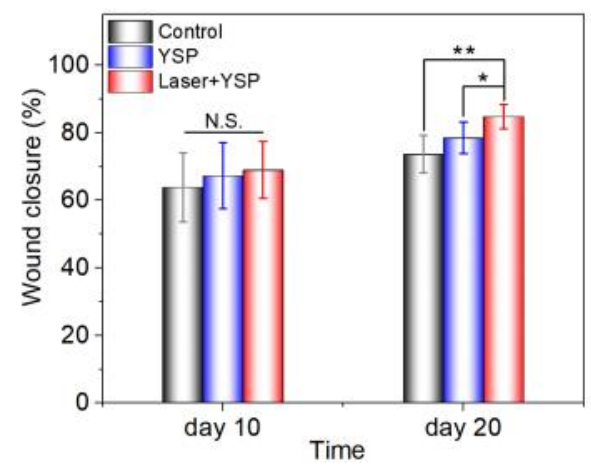

Figure 12. (a) Presentative thermal graphs and (b) temperature rise curve of laser plus YSP group. (c) Photo and (d) data of wound closure of the three groups. N.S. means no significant difference, ${ }^{*} \mathrm{p}<0.05$ and $* * \mathrm{p}<0.01$. 
As demonstrated in Figures 12c and 12d, YSPs and laser irradiation could effectively enhance burn wound healing. The laser assisted YSP group achieved 68.97\% wound closure was after 10 days and $84.84 \%$ wound closure after 20 days. After 20 days, the laser assisted YSP group showed significant difference compared to the other two groups; indicating enhanced wound closure when coupled with laser irradiation. Independent application leads to minimal enhancement towards wound healing.

Histomorphological determination on wound regeneration under different treatment was conducted by H\&E staining and Masson trichrome staining (Figure 13a). Wound regeneration was assessed by observing the re-epithelization, fibroblast immigration, connective tissue synthesis, and collagen production. The wounds treated with the Laser plus YSP almost epithelized in the wound region and the new epidermis was more continuous and uniform than the other groups (Figure 13a). 


\section{(a)}

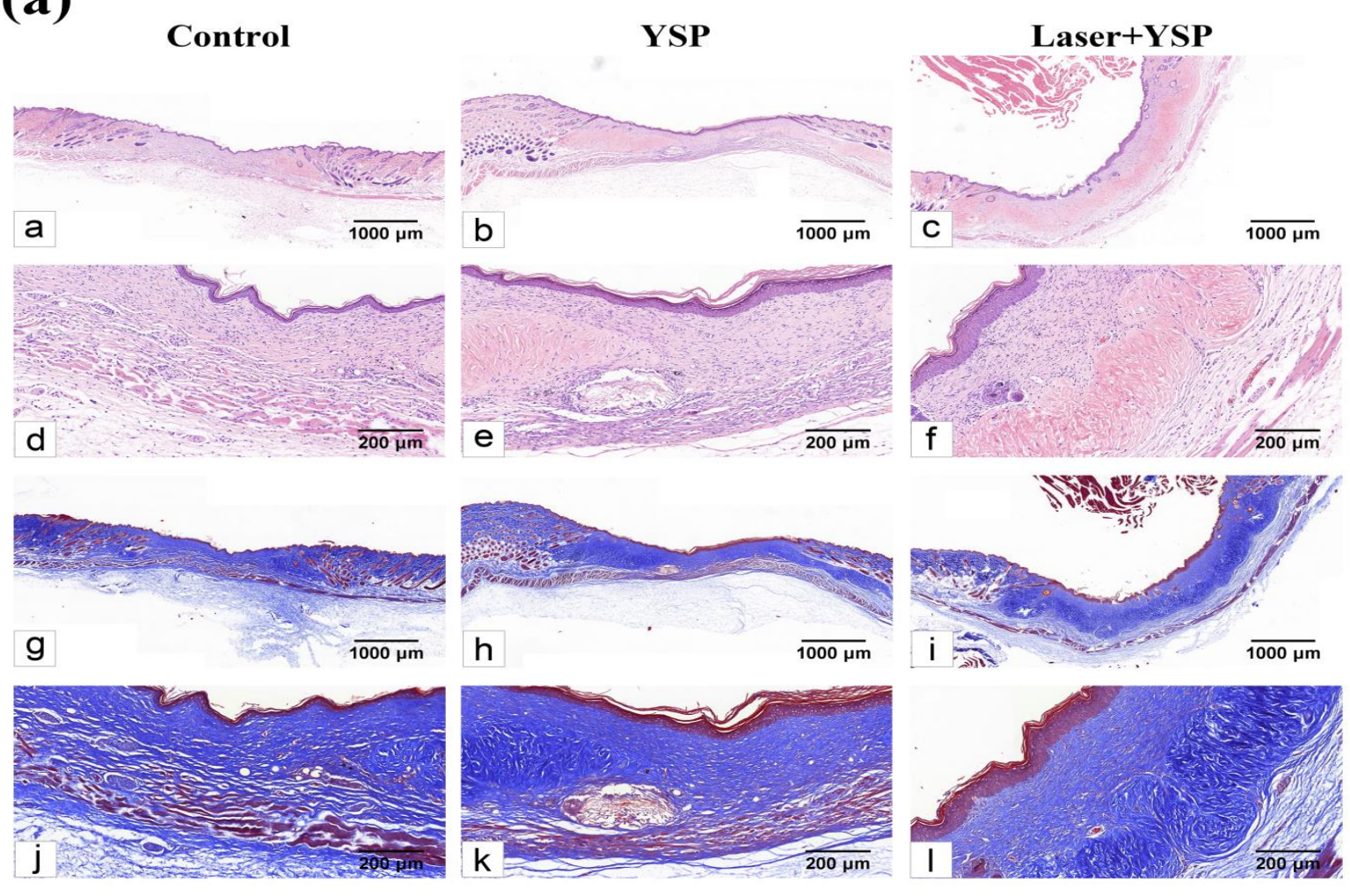

(b)

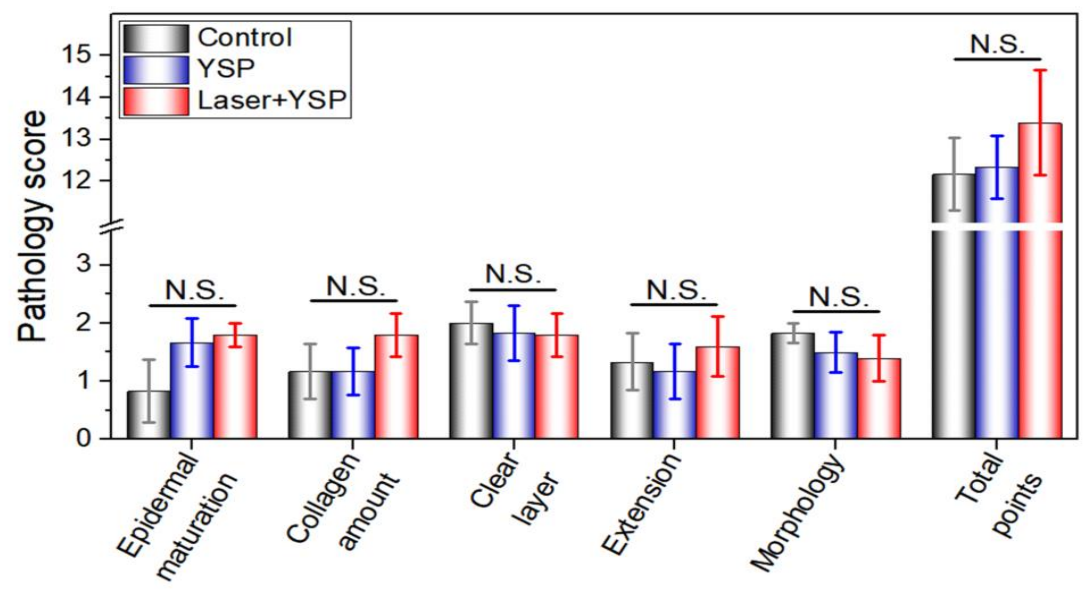

Figure 13. (a) H\&E staining (a-f) and Masson trichrome staining (g-l) and of three groups on day 20. (d-f) and (j-1) are the enlarged micrographs of (a-c) and (g-i), respectively. (b) Pathology score. $(n=6$, day 20). N.S. means no significant difference.

A modified scoring system was used based on a scoring system introduced by Babaeijandaghi et $a l^{54}$ to quantify pathologic findings of $H \& E$ stained and Masson trichrome stained samples. Briefly, totally seven criteria were scored for epidermis and dermis, respectively (Table 1). For 
each criterion, the scoring system was based in order of improving signs from zero to three, that is, the higher score represents better finding for wound repair. The sum of these seven scores was recorded for each group. In summary, the Laser plus YSP group had the best total pathologic score (Figure 13b). In the aspects of epidermal maturation, collagen amount and extension, the laser plus YSP group has the best score. All the samples in the three groups got the same score in dermal-epidermal separation ( 2 points) and PMN amount ( 3 points) which were not shown in Figure 13b. However, scores from three experimental groups show non-significant differences, which may be due to the limited samples in each group. Furthermore, mice recover at a quicker rate than humans.

Table 1. Histologic scoring system.

\begin{tabular}{|c|c|c|c|c|c|c|}
\hline & & & Score & & & \\
\hline & & & 0 & 1 & 2 & 3 \\
\hline \multirow{5}{*}{$\begin{array}{l}\mathrm{H} \& \mathrm{E} \\
\text { staining }\end{array}$} & \multirow{3}{*}{ Epidermis } & Epidermal & None & Mild & Moderate & Full \\
\hline & & maturation & & & & \\
\hline & & $\begin{array}{l}\text { Dermal- } \\
\text { epidermal } \\
\text { separation }\end{array}$ & Diffuse & Focal & None & - \\
\hline & \multirow{2}{*}{ Dermis } & $\begin{array}{l}\text { Collagen } \\
\text { amount }\end{array}$ & None & Scant & Moderate & Abundant \\
\hline & & PMN amount & Abundant & Moderate & Scant & None \\
\hline \multirow{4}{*}{$\begin{array}{l}\text { Masson's } \\
\text { trichrome } \\
\text { staining }\end{array}$} & & Clear layer & None & Blur & Focal & Clear \\
\hline & & Extension & Scant & Scant & Moderate & Abundant \\
\hline & & Morphology & Mostly & Mostly & Mostly & - \\
\hline & & & amorphous & thin wavy & thick wavy & \\
\hline
\end{tabular}




\section{CONCLUSIONS}

In summary, polymer-base YSPs loaded with $\mathrm{TiO}_{2}-\mathrm{Ag}$ particles, GLP and MNP particles were successfully synthesized using tri-needle co-axial electrospraying combined with post treatment of non-solvent. The morphology and internal structure were demonstrated using SEM images. Porous features, magnetic properties, and chemical composition of YSPs were confirmed by BET, VSM, FTIR and DSC/TGA, respectively. In vitro laser assisted drug release was also demonstrated. The YSPs exhibited clear potential as multifunctional platforms for burn wound healing applications. Cell experiments showed good biocompatibility and antioxidant effects of the YSPs. Antibacterial tests indicated the YSPs have outstanding antibacterial activity against $E$. coli and $S$. aureus, especially in liquid condition. In vivo burn wound healing on c57 mice demonstrated that the particles have low bio-toxicity and can promote wound healing in some respects.

\section{AUTHOR INFORMATION}

\section{Corresponding Author}

*Email: mwchang@zju.edu.cn. Tel.: +86 (0)571-87951517. Fax: +86 (0)571-87951517.

\section{Author Contributions}

The manuscript was written through contributions of all authors. All authors have given approval to the final version of the manuscript.

\section{Notes}

The authors declare no competing financial interest. 


\section{ACKNOWLEDGMENT}

This research was financially supported by Major Scientific Project of Zhejiang Lab (No. 2018DG0ZX01), the National Nature Science Foundation of China (No. 81771960), the

Fundamental Research Funds for the Central Universities (2017QNA5017) and Key Technologies R\&D Program of Zhejiang Province (2015C02035).

\section{REFERENCES}

(1) Si, Y.; Chen, M.; Wu, L. Syntheses and Biomedical Applications of Hollow Micro-/NanoSpheres with Large-through-Holes. Chem. Soc. Rev. 2016, 45, 690-714.

(2) Gu, J.; Zhang, Q.; Dang, J.; Yin, C.; Chen, S. Preparation and Properties of Polystyrene/Sicw/Sicp Thermal Conductivity Composites. J. Appl. Polym. Sci. 2012, 124, 132137.

(3) Yoo, J.-W.; Doshi, N.; Mitragotri, S. Adaptive Micro and Nanoparticles: Temporal Control over Carrier Properties to Facilitate Drug Delivery. Adv. Drug Delivery Rev. 2011, 63, 12471256.

(4) Yan, S. F.; Xia, P. F.; Xu, S. H.; Zhang, K. X.; Li, G. F.; Cui, L.; Yin, J. B. Nanocomposite Porous Microcarriers Based on Strontium Substituted Ha-G-Poly(Gamma-Benzyl-L-Glutamate) for Bone Tissue Engineering. ACS Appl. Mater. Interfaces 2018, 10, 16270-16281.

(5) Guo, X. M.; Li, W.; Luo, L. H.; Wang, Z. H.; Li, Q. P.; Kong, F. F.; Zhang, H. B.; Yang, J.; Zhu, C. Q.; Du, Y. Z.; You, J. External Magnetic Field-Enhanced Chemo-Photothermal Combination Tumor Therapy Via Iron Oxide Nanoparticles. ACS Appl. Mater. Interfaces 2017, 9 , 16581-16593.

(6) Gao, Y.; Bai, Y.; Zhao, D.; Chang, M.-W.; Ahmad, Z.; Li, J.-S. Tuning Microparticle Porosity During Single Needle Electrospraying Synthesis Via a Non-Solvent-Based Physicochemical Approach. Polymers 2015, 7, 2701-2710.

(7) Liu, J.; Qiao, S. Z.; Hartono, S. B.; Lu, G. Q. Monodisperse Yolk-Shell Nanoparticles with a Hierarchical Porous Structure for Delivery Vehicles and Nanoreactors. Angew. Chem. Int. Ed. 2010, 49, 4981-4985.

(8) Walther, A.; Müller, A. H. E. Janus Particles: Synthesis, Self-Assembly, Physical Properties, and Applications. Chem. Rev. 2013, 113, 5194-5261.

(9) Chen, J.; Ratnayaka, S.; Alford, A.; Kozlovskaya, V.; Liu, F.; Xue, B.; Hoyt, K.; Kharlampieva, E. Theranostic Multilayer Capsules for Ultrasound Imaging and Guided Drug Delivery. ACS Nano 2017, 11, 3135-3146.

(10) Liberman, A.; Wang, J.; Lu, N.; Viveros, R. D.; Allen, C. A.; Mattrey, R. F.; Blair, S. L.; Trogler, W. C.; Kim, M. J.; Kummel, A. C. Mechanically Tunable Hollow Silica Ultrathin Nanoshells for Ultrasound Contrast Agents. Adv. Funct. Mater. 2015, 25, 4049-4057.

(11) Tanaka, T.; Okayama, M.; Kitayama, Y.; Kagawa, Y.; Okubo, M. Preparation of "Mushroom-Like" Janus Particles by Site-Selective Surface-Initiated Atom Transfer Radical 
Polymerization in Aqueous Dispersed Systems. Langmuir 2010, 26, 7843-7847.

(12) Chang, M.-W.; Stride, E.; Edirisinghe, M. A New Method for the Preparation of Monoporous Hollow Microspheres. Langmuir 2010, 26, 5115-5121.

(13) Song, J.; Yan, P.; Luo, L.; Qi, X.; Rong, X.; Zheng, J.; Xiao, B.; Feng, S.; Wang, C.; Hu, Y.S.; Lin, Y.; Sprenkle, V. L.; Li, X. Yolk-Shell Structured Sb@C Anodes for High Energy Na-Ion Batteries. Nano Energy 2017, 40, 504-511.

(14) Shao, A.; Xie, Y.; Zhu, S.; Guo, Z.; Zhu, S.; Guo, J.; Shi, P.; James, T. D.; Tian, H.; Zhu, W. H. Far - Red and near - Ir Aie - Active Fluorescent Organic Nanoprobes with Enhanced Tumor - Targeting Efficacy: Shape - Specific Effects. Angew. Chem. Int. Ed. 2015, 54, 72757280 .

(15) Freiberg, S.; Zhu, X. X. Polymer Microspheres for Controlled Drug Release. Int. J. Pharm. 2004, 282, 1-18.

(16) Qutachi, O.; Vetsch, J. R.; Gill, D.; Cox, H.; Scurr, D. J.; Hofmann, S.; Müller, R.; Quirk, R. A.; Shakesheff, K. M.; Rahman, C. V. Injectable and Porous Plga Microspheres That Form Highly Porous Scaffolds at Body Temperature. Acta Biomater. 2014, 10, 5090-5098.

(17) Itoh, Y.; Matsusaki, M.; Kida, T.; Akashi, M. Enzyme-Responsive Release of Encapsulated Proteins from Biodegradable Hollow Capsules. Biomacromolecules 2006, 7, 2715-2718.

(18) Purbia, R.; Paria, S. Yolk/Shell Nanoparticles: Classifications, Synthesis, Properties, and Applications. Nanoscale 2015, 7, 19789-19873.

(19) Patel, S. K. S.; Anwar, M. Z.; Kumar, A.; Otari, S. V.; Pagolu, R. T.; Kim, I.-W.; Kim, S.-Y.; Lee, J.-K. Fe2o3 Yolk-Shell Particle-Based Laccase Biosensor for Efficient Detection of 2,6Dimethoxyphenol. Biochem. Eng. J. 2018, 132, 1-8.

(20) Lin, L. S.; Song, J. B.; Yang, H. H.; Chen, X. Y. Yolk-Shell Nanostructures: Design, Synthesis, and Biomedical Applications. Adv. Mater. 2018, 30, 1704639.

(21) Wang, Y.-X.; Yang, J.; Chou, S.-L.; Liu, H. K.; Zhang, W.-X.; Zhao, D.; Dou, S. X. Uniform Yolk-Shell Iron Sulfide-Carbon Nanospheres for Superior Sodium-Iron Sulfide Batteries. Nat. Commun. 2015, 6, 8689.

(22) Liu, Z.; Yu, X. Y.; Paik, U. Etching - in - a - Box: A Novel Strategy to Synthesize Unique Yolk - Shelled Fe3o4@Carbon with an Ultralong Cycling Life for Lithium Storage. Adv. Energy Mater. 2016, 6, 1502318.

(23) Akbarzadeh, H.; Mehrjouei, E.; Shamkhali, A. N.; Abbaspour, M.; Salemi, S.; Ramezanzadeh, S. Au@Void@Agau Yolk-Shell Nanoparticles with Dominant Strain Effects: A Molecular Dynamics Simulation. J. Phys. Chem. Lett. 2017, 8, 5064-5068.

(24) Guo, S. C.; Hu, X.; Hou, Y.; Wen, Z. H. Tunable Synthesis of Yolk-Shell Porous Silicon@Carbon for Optimizing Si/C-Based Anode of Lithium-Ion Batteries. ACS Appl. Mater. Interfaces 2017, 9, 42084-42092.

(25) Do, Q. C.; Kim, D.-G.; Ko, S.-O. Catalytic Activity Enhancement of a Fe3o4@Sio2 YolkShell Structure for Oxidative Degradation of Acetaminophen by Decoration with Copper. $J$. Cleaner Prod. 2018, 172, 1243-1253.

(26) Gu, J.; Wang, L.; Liang, C.; Zhuang, Q.; Kong, J. Controlled Shell on Nanoparticles as a Tool to Regulate the Properties of Immobilized Molecules. J. Alloys Compd. 2018, 745, 430-435. (27) Bondarenko, O.; Juganson, K.; Ivask, A.; Kasemets, K.; Mortimer, M.; Kahru, A. Toxicity of Ag, Cuo and Zno Nanoparticles to Selected Environmentally Relevant Test Organisms and Mammalian Cells in Vitro: A Critical Review. Arch. Toxicol. 2013, 87, 1181-1200.

(28) Ulery, B. D.; Nair, L. S.; Laurencin, C. T. Biomedical Applications of Biodegradable Polymers. J. Polym. Sci., Part B: Polym. Phys. 2011, 49, 832-864. 
(29) Kim, W.; Kim, S. S. Synthesis of Biodegradable Triple-Layered Capsules Using a Triaxial Electrospray Method. Polymer 2011, 52, 3325-3336.

(30) Gao, J.; Li, R. K. Y.; Li, W.; Wong, J. S.-P.; Hu, M. Controllable Morphology and Wettability of Polymer Microspheres Prepared by Nonsolvent Assisted Electrospraying. Polymer 2014, 55, 2913-2920.

(31) Zhang, C. C.; Yao, Z. C.; Ding, Q. P.; Choi, J. J.; Ahmad, Z.; Chang, M. W.; Li, J. S. TriNeedle Coaxial Electrospray Engineering of Magnetic Polymer Yolk-Shell Particles Possessing Dual-Imaging Modality, Multiagent Compartments, and Trigger Release Potential. ACS Appl. Mater. Interfaces 2017, 9, 21485-21495.

(32) Yang, M.; Lai, S. K.; Wang, Y.-Y.; Zhong, W.; Happe, C.; Zhang, M.; Fu, J.; Hanes, J. Biodegradable Nanoparticles Composed Entirely of Safe Materials That Rapidly Penetrate Human Mucus. Angew. Chem. Int. Ed. 2011, 50, 2597-2600.

(33) Wu, T.-S.; Wang, K.-X.; Li, G.-D.; Sun, S.-Y.; Sun, J.; Chen, J.-S. MontmorilloniteSupported Ag/Tio2 Nanoparticles: An Efficient Visible-Light Bacteria Photodegradation Material. ACS Appl. Mater. Interfaces 2010, 2, 544-550.

(34) Li, M. H.; Noriega-Trevino, M. E.; Nino-Martinez, N.; Marambio-Jones, C.; Wang, J. W.; Damoiseaux, R.; Ruiz, F.; Hoek, E. M. V. Synergistic Bactericidal Activity of Ag-Tio2 Nanoparticles in Both Light and Dark Conditions. Environ. Sci. Technol. 2011, 45, 8989-8995.

(35) Luo, Y.; Diao, H.; Xia, S.; Dong, L.; Chen, J.; Zhang, J. A Physiologically Active Polysaccharide Hydrogel Promotes Wound Healing. J. Biomed. Mater. Res., Part A 2010, 94, 193-204.

(36) Tie, L.; Yang, H.-Q.; An, Y.; Liu, S.-Q.; Han, J.; Xu, Y.; Hu, M.; Li, W.-D.; Chen, A. F.; Lin, Z.-B.; Li, X.-J. Ganoderma Lucidum Polysaccharide Accelerates Refractory Wound Healing by Inhibition of Mitochondrial Oxidative Stress in Type 1 Diabetes. Cell. Physiol. Biochem. 2012, 29, 583-594.

(37) Guo, X.; Wu, Z.; Li, W.; Wang, Z.; Li, Q.; Kong, F.; Zhang, H.; Zhu, X.; Du, Y. P.; Jin, Y.; $\mathrm{Du}$, Y.; You, J. Appropriate Size of Magnetic Nanoparticles for Various Bioapplications in Cancer Diagnostics and Therapy. ACS Appl. Mater. Interfaces 2016, 8, 3092-3106.

(38) Yao, Z.-C.; Jin, L.-J.; Ahmad, Z.; Huang, J.; Chang, M.-W.; Li, J.-S. Ganoderma Lucidum Polysaccharide Loaded Sodium Alginate Micro-Particles Prepared Via Electrospraying in Controlled Deposition Environments. Int. J. Pharm. 2017, 524, 148-158.

(39) Aoyagi, S.; Onishi, H.; Machida, Y. Novel Chitosan Wound Dressing Loaded with Minocycline for the Treatment of Severe Burn Wounds. Int. J. Pharm. 2007, 330, 138-145.

(40) Thommes, M.; Kaneko, K.; Neimark, A. V.; Olivier, J. P.; Rodriguez-Reinoso, F.; Rouquerol, J.; Sing, K. S. W. Physisorption of Gases, with Special Reference to the Evaluation of Surface Area and Pore Size Distribution (Iupac Technical Report). Pure Appl. Chem. 2015, 87, 1051-1069.

(41) Zhao, L.; Dong, Y.; Chen, G.; Hu, Q. Extraction, Purification, Characterization and Antitumor Activity of Polysaccharides from Ganoderma Lucidum. Carbohydr. Polym. 2010, 80, 783-789.

(42) Yang, Y.; Wen, J.; Wei, J.; Xiong, R.; Shi, J.; Pan, C. Polypyrrole-Decorated Ag-Tio2 Nanofibers Exhibiting Enhanced Photocatalytic Activity under Visible-Light Illumination. ACS Appl. Mater. Interfaces 2013, 5, 6201-6207.

(43) Zhou, W.; Hu, X.; Bai, X.; Zhou, S.; Sun, C.; Yan, J.; Chen, P. Synthesis and Electromagnetic, Microwave Absorbing Properties of Core-Shell Fe3o4-Poly(3,4Ethylenedioxythiophene) Microspheres. ACS Appl. Mater. Interfaces 2011, 3, 3839-3845. 
(44) Wang, J. C.; Zheng, H. X.; Chang, M. W.; Ahmad, Z. S.; Li, J. S. Preparation of Active 3d Film Patches Via Aligned Fiber Electrohydrodynamic (Ehd) Printing. Sci. Rep. 2017, 7, 43924.

(45) Yao, Z.-C.; Zhang, C.; Ahmad, Z.; Huang, J.; Li, J.-S.; Chang, M.-W. Designer Fibers from $2 \mathrm{~d}$ to $3 \mathrm{~d}-$ Simultaneous and Controlled Engineering of Morphology, Shape and Size. Chem. Eng. J. 2018, 334, 89-98.

(46) Qian, J.-Y.; Chen, W.; Zhang, W.-M.; Zhang, H. Adulteration Identification of Some Fungal Polysaccharides with Sem, Xrd, Ir and Optical Rotation: A Primary Approach. Carbohydr. Polym. 2009, 78, 620-625.

(47) Chuang, H.-Y.; Chen, D.-H. Fabrication and Photocatalytic Activities in Visible and Uv Light Regions of Ag@Tio2 and Niag@Tio2 Nanoparticles. Nanotechnology 2009, 20, 105704. (48) Li, Z.-T.; Li, D.-H.; Lin, B.; Lin, E.-C.; Jiang, L.-W.; Chen, J.; Zhang, S.-J.; Tang, Y.-W.; He, F.-A. Effective Preparation of Magnetic Superhydrophobic Fe3o4/Pu Sponge for Oil-Water Separation. Appl. Surf. Sci. 2018, 427, 56-64.

(49) Dhanka, M.; Shetty, C.; Srivastava, R. Injectable Methotrexate Loaded Polycaprolactone Microspheres: Physicochemical Characterization, Biocompatibility, and Hemocompatibility Evaluation. Mater. Sci. Eng., C 2017, 81, 542-550.

(50) Amalorpava Mary, L.; Senthilram, T.; Suganya, S.; Nagarajan, L.; Venugopal, J.; Ramakrishna, S.; Giri Dev, V. R. Centrifugal Spun Ultrafine Fibrous Web as a Potential Drug Delivery Vehicle. eXPRESS Polym. Lett. 2012, 7, 238-248.

(51) Wang, Y. P.; Liao, Y. T.; Liu, C. H.; Yu, J. S.; Alamri, H. R.; Alothman, Z. A.; Hossain, M. S. A.; Yamauchi, Y.; Wu, K. C. W. Trifunctional Fe3o4/Cap/Alginate Core-Shell-Corona Nanoparticles for Magnetically Guided, Ph-Responsive, and Chemically Targeted Chemotherapy. ACS Biomater. Sci. Eng. 2017, 3, 2366-2374.

(52) Chen, M.; He, Y.; Huang, J.; Zhu, J. Synthesis and Solar Photo-Thermal Conversion of Au, Ag, and Au-Ag Blended Plasmonic Nanoparticles. Energy Convers. Manage. 2016, 127, 293300 .

(53) Kalyanaraman, B.; Darley-Usmar, V.; Davies, K. J. A.; Dennery, P. A.; Forman, H. J.; Grisham, M. B.; Mann, G. E.; Moore, K.; Roberts, L. J.; Ischiropoulos, H. Measuring Reactive Oxygen and Nitrogen Species with Fluorescent Probes: Challenges and Limitations. Free Radical Biol. Med. 2012, 52, 1-6.

(54) Babaeijandaghi, F.; Shabani, I.; Seyedjafari, E.; Naraghi, Z. S.; Vasei, M.; Haddadi-Asl, V.; Hesari, K. K.; Soleimani, M. Accelerated Epidermal Regeneration and Improved Dermal Reconstruction Achieved by Polyethersulfone Nanofibers. Tissue Eng., Part A 2010, 16, 35273536. 
TOC Figure

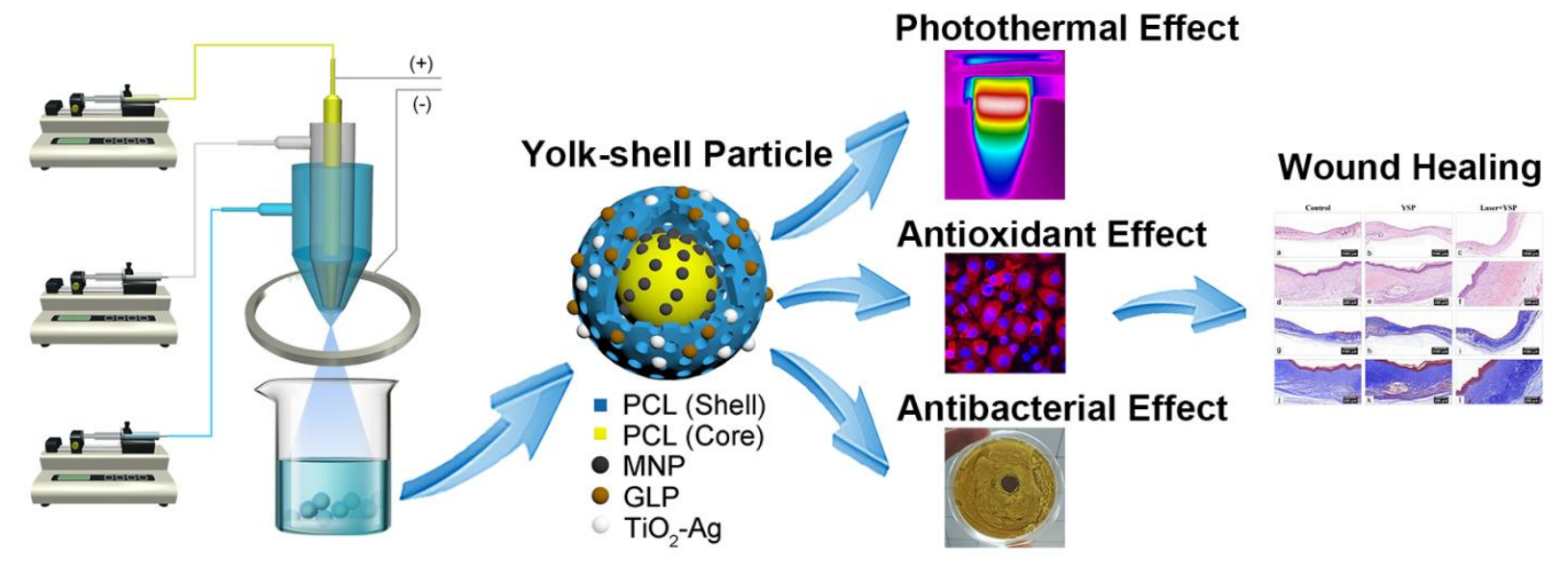

